\title{
The coupling of dynamics and permeability in the hydrocarbon accumulation period controls the oil-bearing potential of low permeability reservoirs: a case study of the low permeability turbidite reservoirs in the middle part of the third member of Shahejie Formation in Dongying Sag
}

\author{
Tian Yang ${ }^{1,2,3} \cdot$ Ying-Chang Cao ${ }^{1,2} \cdot$ Yan-Zhong Wang ${ }^{1,2} \cdot$ Henrik Friis $^{3} \cdot$ \\ Beyene Girma Haile $^{4} \cdot$ Ke-Lai Xi ${ }^{1,2,4} \cdot$ Hui-Na Zhang ${ }^{1,2}$ \\ Received: 24 March 2015/Published online: 29 April 2016 \\ (c) The Author(s) 2016. This article is published with open access at Springerlink.com
}

\begin{abstract}
The relationships between permeability and dynamics in hydrocarbon accumulation determine oilbearing potential (the potential oil charge) of low permeability reservoirs. The evolution of porosity and permeability of low permeability turbidite reservoirs of the middle part of the third member of the Shahejie Formation in the Dongying Sag has been investigated by detailed core descriptions, thin section analyses, fluid inclusion analyses, carbon and oxygen isotope analyses, mercury injection, porosity and permeability testing, and basin modeling. The cutoff values for the permeability of the reservoirs in the accumulation period were calculated after detailing the accumulation dynamics and reservoir pore structures, then the distribution pattern of the oil-bearing potential of reservoirs controlled by the matching relationship between dynamics and permeability during the accumulation period were summarized. On the basis of the observed diagenetic features and with regard to the paragenetic sequences, the reservoirs can be subdivided into four types of diagenetic facies. The reservoirs experienced two periods of hydrocarbon accumulation. In the early accumulation period, the
\end{abstract}

Ying-Chang Cao

cyc8391680@163.com

1 School of Geosciences, China University of Petroleum, Qingdao 266580, Shandong, China

2 Laboratory for Marine Mineral Resources, Qingdao National Laboratory for Marine Science and Technology, Qingdao 266071, China

3 Department of Geoscience, Aarhus University, HøeghGuldbergs Gade 2, 8000 Aarhus C, Denmark

4 Department of Geosciences, University of Oslo, P.O. Box 1047, Blindern, 0316 Oslo, Norway

Edited by Jie Hao reservoirs except for diagenetic facies A had middle to high permeability ranging from $10 \times 10^{-3} \mu^{2}$ to $4207 \times 10^{-3} \mu \mathrm{m}^{2}$. In the later accumulation period, the reservoirs except for diagenetic facies $\mathrm{C}$ had low permeability ranging from $0.015 \times 10^{-3} \mu \mathrm{m}^{2}$ to $62 \times 10^{-3} \mu \mathrm{m}^{2}$. In the early accumulation period, the fluid pressure increased by the hydrocarbon generation was $1.4-11.3 \mathrm{MPa}$ with an average value of $5.1 \mathrm{MPa}$, and a surplus pressure of 1.8-12.6 MPa with an average value of 6.3 MPa. In the later accumulation period, the fluid pressure increased by the hydrocarbon generation process was $0.7-12.7 \mathrm{MPa}$ with an average value of $5.36 \mathrm{MPa}$ and a surplus pressure of 1.3-16.2 MPa with an average value of $6.5 \mathrm{MPa}$. Even though different types of reservoirs exist, all can form hydrocarbon accumulations in the early accumulation period. Such types of reservoirs can form hydrocarbon accumulation with high accumulation dynamics; however, reservoirs with diagenetic facies $\mathrm{A}$ and diagenetic facies $\mathrm{B}$ do not develop accumulation conditions with low accumulation dynamics in the late accumulation period for very low permeability. At more than $3000 \mathrm{~m}$ burial depth, a larger proportion of turbidite reservoirs are oil charged due to the proximity to the source rock. Also at these depths, lenticular sand bodies can accumulate hydrocarbons. At shallower depths, only the reservoirs with oil-source fault development can accumulate hydrocarbons. For flat surfaces, hydrocarbons have always been accumulated in the reservoirs around the oil-source faults and areas near the center of subsags with high accumulation dynamics.

Keywords Reservoir porosity and permeability evolution - Accumulation dynamics - Cutoff-values of permeability in the accumulation period . Oil-bearing potential $\cdot$ Low permeability reservoir . The third member of the Shahejie Formation · Dongying Sag 


\section{Introduction}

With the increasing interest in oil and gas exploration and development, low permeability clastic rock reservoirs are becoming key exploration target areas (Yang et al. 2010; Cao et al. 2012). The low permeability clastic rock reservoirs have gone through complex diagenetic events (Yang et al. 2010; Wang et al. 2011). The distribution of sandstone porosity is not consistent with the hydrocarbon accumulation. The porosity of sandstone during the accumulation period is the key factor to determine the oiliness of the reservoirs (Cao et al. 2012; Liu et al. 2014a; Wang et al. 2014a). Some researchers have attempted to extract data from the porosity of low permeability clastic rock reservoirs during the accumulation period (Cao et al. 2011, 2012, 2013; Wang et al. 2013a; Liu et al. 2014a). However, they did not calculate the cutoff values for porosity of the reservoir under the control of accumulation dynamics during the accumulation period (Pan et al. 2011; Wang et al. 2014a; Liu et al. 2014a). The distribution of the oilbearing potential of reservoirs is still poorly understood. The relationships between porosity and the oil-bearing potential of turbidite reservoirs of the middle part of the third member of Shahejie Formation $\left(\mathrm{Es}_{3}^{\mathrm{z}}\right)$ in Dongying Sag are complex, even though the reservoirs have similar accumulation conditions. The high or low porosity and permeability sandstone reservoirs either contain oil or not. Liu et al. (2014a, b) analyzed the relationship between porosity and the cutoff-values for porosity in the early accumulation period of $\mathrm{Es}_{3}^{\mathrm{z}}$ turbidite reservoirs in Niuzhuang subsag with the guide of porosity estimation and effect-oriented simulation. They concluded that the porosity of reservoirs in the early accumulation period was higher than the cutoff-values for porosity of the reservoirs. So the reservoirs could be charged with oil. The permeability is the main controlling factor for percolation and the development of low permeability reservoirs (Meng et al. 2013). There were several stages of accumulation for the $\mathrm{Es}_{3}^{\mathrm{Z}}$ turbidite reservoirs in the Dongying Sag and the later accumulation period was the most important (Cai 2009). The permeability and the cutoff-values at the later accumulation period are the most important for the distribution of the oil-bearing potential of reservoirs today.

On the basis of previous studies, taking the $\mathrm{Es}_{3}^{\mathrm{z}}$ turbidite reservoirs as an example, the permeability of the reservoirs in the accumulation period was estimated. The permeability estimation method was based on the paragenetic sequence of diagenetic minerals and the reservoir pore-throat geometry. The cutoff-values for permeability of reservoirs in the accumulation period are calculated after the estimation of accumulation dynamics and reservoir pore-throat geometries, and finally the distribution pattern of the oil-bearing potential of the reservoirs is determined. This can provide theoretical guidance for the exploration and development of low permeability turbidite reservoirs.

\section{Geological background}

The Dongying Sag is a sub-tectonic unit lying in the southeastern part of the Jiyang Depression of the Bohai Bay Basin, East China. It is a Mesozoic-Cenozoic half graben rift-downwarped basin with lacustrine facies directly deposited on Paleozoic bedrocks (Cao et al. 2014; Wang et al. 2014b). The Dongying Sag is bounded to the east by the Qingtuozi Salient, to the south by the Luxi Uplift and Guangrao Salient, to the west by the Linfanjia and Gaoqing salients, and to the north by the Chenjiazhuang-Binxian Salient. The NE-trending sag covers an area of $5850 \mathrm{~km}^{2}$ (Fig. 1). It is a half graben with a faulted northern margin and a gentle southern margin. Horizontally, this sag is further subdivided into several secondary structural units, such as the northern steep slope zone, middle uplift belt, and the Lijin, Minfeng and Niuzhuang trough zones, Boxing subsag, and the southern gentle zone (Zhang et al. 2014). The sag is filled with Cenozoic sediments, which are formations from the Paleogene, Neogene, and Quaternary periods. The formations from the Paleogene period are the Kongdian (Ek), Shahejie (Es), and Dongying (Ed); the formations from the Neogene period are the Guantao $(\mathrm{Ng})$ and Minghuazhen $(\mathrm{Nm})$; and the formation from the Quaternary period is the Pingyuan (Qp). Detailed descriptions of the Paleogene stratigraphy have been provided by several authors (Zhang et al. 2004, 2010; Guo et al. 2012) (Fig. 2).

During the deposition of the third member of the Shahejie Formation, tectonic movement was strong, and the basin subsided rapidly reaching its maximum depth. As a result, large amounts of detrital materials were transported into the basin and formed plentiful source rocks and turbidites in deep-water environments in the depressed zone and uplifted zone (Wang et al. 2013b; Yang et al. 2015) (Fig. 3). The thickness of single sand layers of turbidite reservoirs is $0.1-0.5 \mathrm{~m}$; the accumulation thickness is $10-158 \mathrm{~m}$. Turbidity current deposits with Bouma sequences and debris flow deposits with massive bedding are most common. The east slope of the Niuzhuang subsag, Liangjialou, and the front of the Dongying delta are places where a large volume of turbidites are distributed (Yang et al. 2015). Most turbidite reservoirs are low permeability with complex oil-bearing characteristics. 


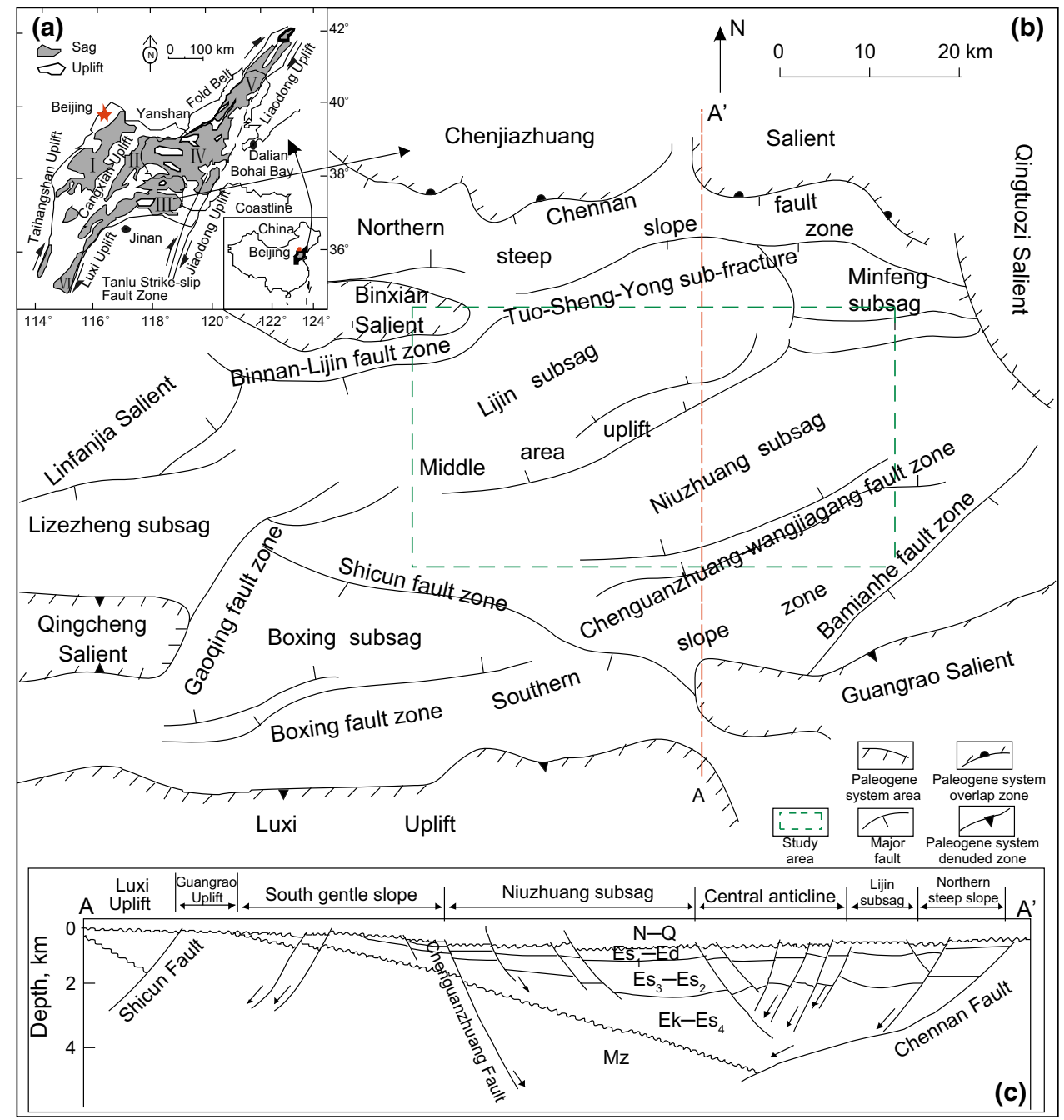

Fig. 1 a Location map showing the six major sub basins of the Bohai Bay Basin. b Structural map of the Dongying Sag. The area in the green line box is the study area (After Liu et al. 2014a). c N-S cross section ( $\left.\mathrm{A}^{\prime}-\mathrm{A}\right)$ of the Dongying Sag showing the various tectonic-structural zones and key stratigraphic intervals

\section{Materials and methods}

Over $1500 \mathrm{~m}$ of representative cores of turbidite in the target formation have been described. 119 typical samples were taken from the core. Thin section examination and porosity and permeability testing of all 119 samples were undertaken. Mercury injection testing of 90 samples, scanning electron microscopy (SEM) examination of 15 samples, cathode luminescence testing of 17 samples, fluorescence thin section observation of 17 samples, and fluid inclusion testing of 53 samples were undertaken. The core samples were provided by the Geological Scientific Research Institute of the Sinopec Shengli Oilfield Company. Porosity, permeability, and mercury injections were measured at the Exploration and Development Research Institute of the Sinopec Zhongyuan Oilfield Company as were the SEM examinations. Porosity and permeability were tested by a 3020-62 helium porosity analyzer and GDS-9F gas permeability analyzer at common temperature and humidity. Mercury injection was tested by a 9505 mercury injection analyzer at $22{ }^{\circ} \mathrm{C}$ and $60 \%$ humidity. Samples were examined by a JSM-5500LVSEM combined with QUANTAX400 energy dispersive X-ray microanalyser (EDX). The thin sections and fluorescence thin sections were prepared by the CNPC Key Laboratory of Oil and Gas reservoirs at the China University of Petroleum and were examined using an Axioscope A1 APOL digital polarizing microscope produced by the German company Zeiss. The cathodoluminescence was studied using an Imager D2 m cathode luminescence microscope also produced by Zeiss. The fluid inclusions were analyzed using a THMSG600 conventional inclusion temperature measurement system produced by the British Company Linkam. Sandstone composition analysis data of 2314 samples and 


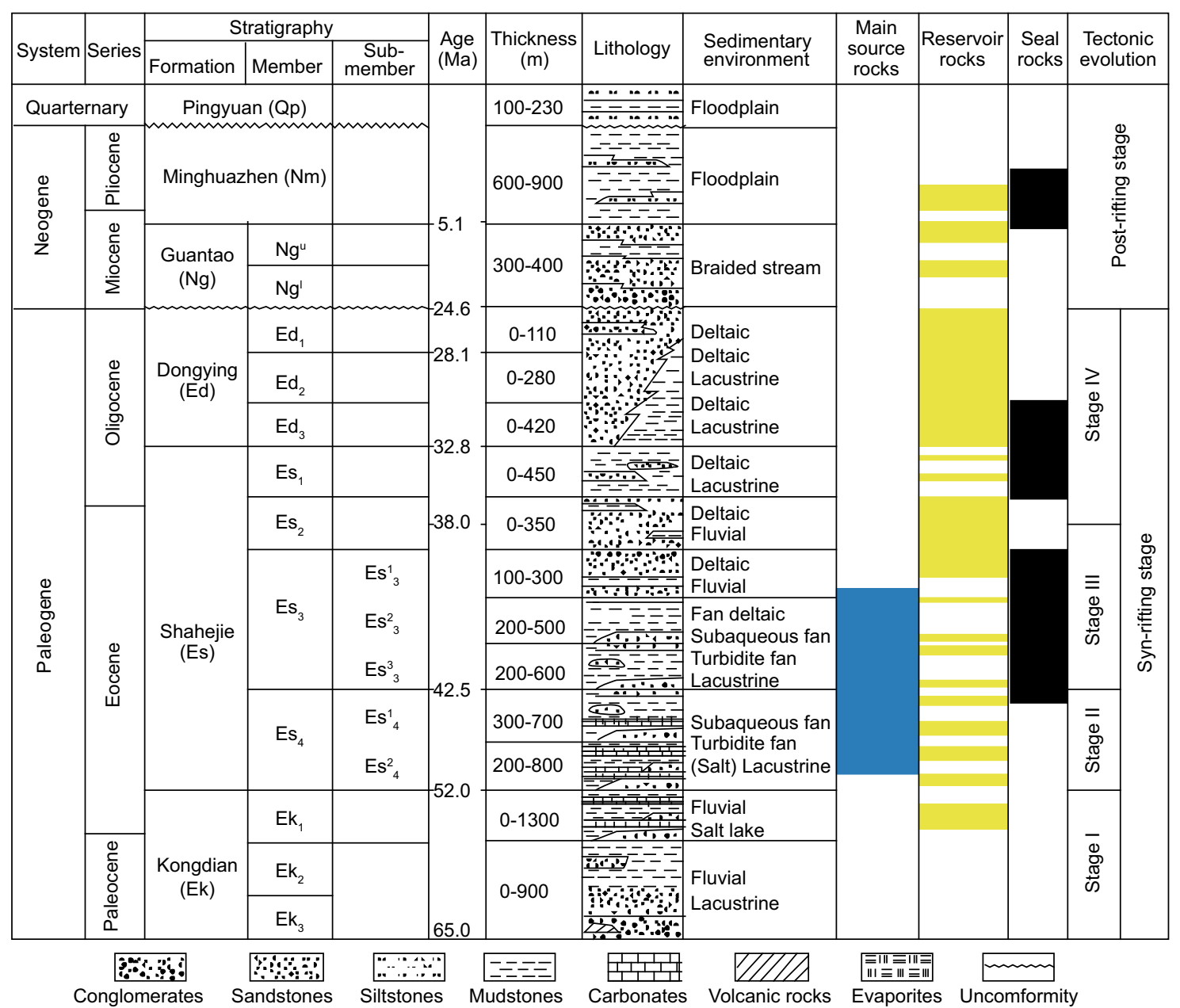

Fig. 2 Generalized Cenozoic Quaternary stratigraphy of the Dongying Sag, showing tectonic and sedimentary evolution stages and the major petroleum system elements (After Yuan et al. 2015)

porosity and permeability testing of 7433 samples of the research area have been collected from the Geological Scientific Research Institute of the Sinopec Shengli Oilfield Company.

\section{Characteristics and porosity-permeability evolution of low permeability turbidite reservoirs}

\subsection{Characteristics of low permeability turbidite reservoirs}

\subsubsection{Petrography}

$\mathrm{Es}_{3}^{\mathrm{z}}$ turbidite sandstones from the Dongying Sag predominantly belong to lithic arkose families based on the sandstones classification scheme of Folk (1974) (Fig. 4). The reservoirs are mainly composed of fine to medium grained sandstones. Based on the amount of framework grains, the quartz content is $29 \%-69.2 \%$ with an average of $43.5 \%$; the feldspar content is $14.3 \%-47 \%$ with an average of $33.7 \%$; the content of rock fragments is $2 \%-44.2 \%$ with an average of $22.8 \%$. The mud content is $0.5 \%-48 \%$ with an average of $11.0 \%$, and the cement content is $0.5 \%-34.6 \%$ with an average of $8.2 \%$. The compositional maturity is $0.41-2.25$ with an average of 0.8 , and detrital grains are moderately sorted, with sub-angular or sub-rounded shapes.

\subsubsection{Reservoir features}

\section{(1) Porosity-permeability}

Based on the porosity-permeability data, the study area is characterized by low permeability with an average porosity and permeability value of $17.1 \%$ and $38.1 \times 10^{-3} \mu \mathrm{m}^{2}$, respectively. It contains $31 \%$ low porosity reservoirs, $69 \%$ medium to high porosity reservoirs, $88 \%$ low 


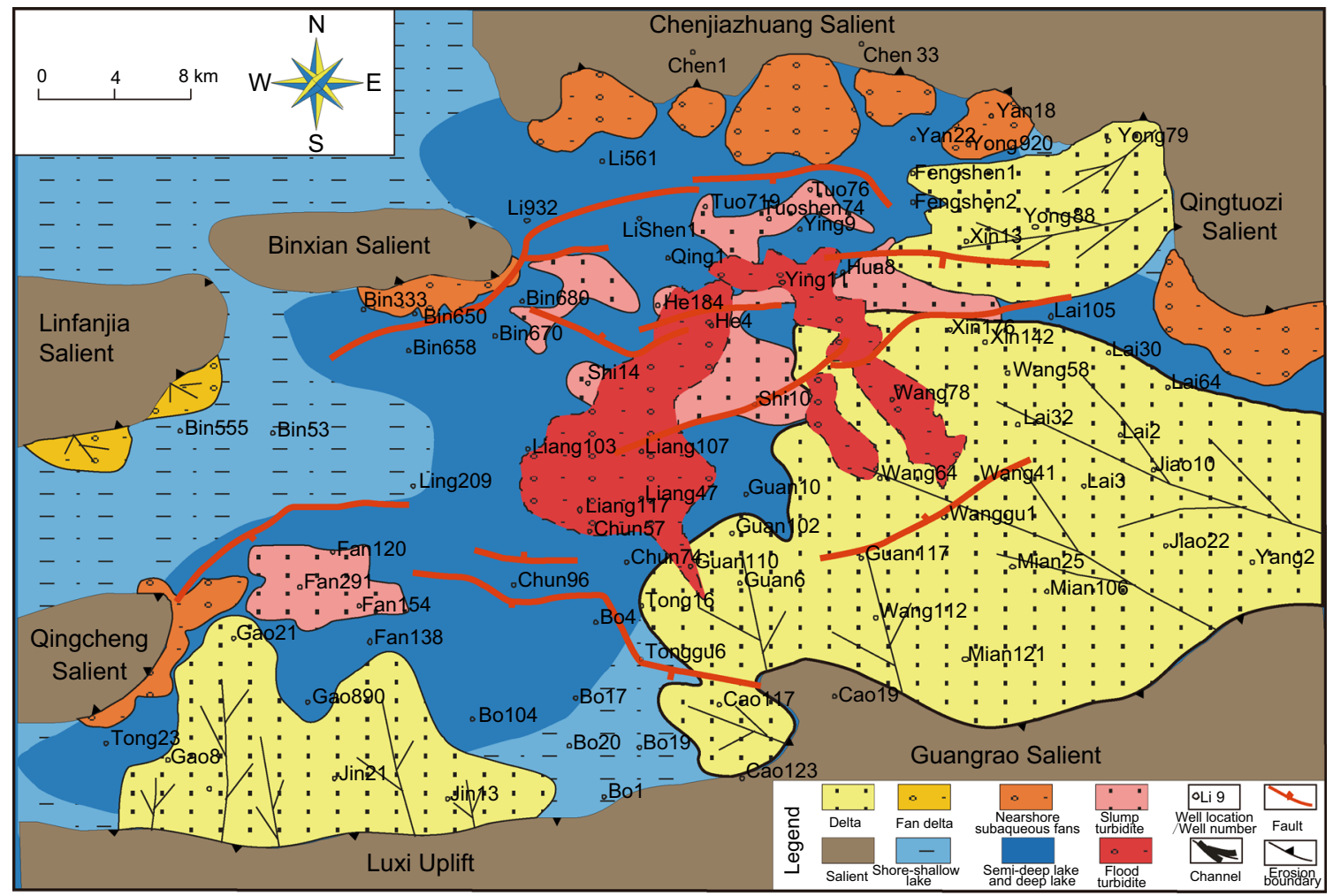

Fig. 3 Sedimentary facies distribution of $\mathrm{Es}_{3}^{\mathrm{z}}$ in Dongying Sag

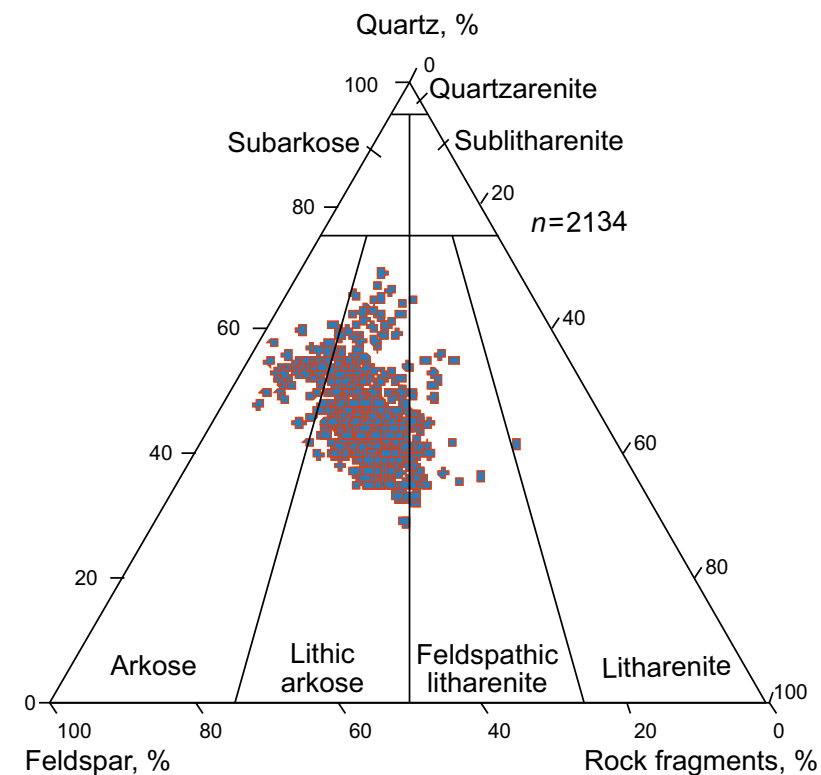

Fig. 4 Triangular plot of sandstones of the low permeability $\mathrm{Es}_{3}^{\mathrm{Z}}$ turbidite reservoirs

permeability reservoirs, and $12 \%$ medium to high permeability reservoirs. Low permeability reservoirs with middle-high porosity are most common with $59 \%$ of the total reservoirs (Fig. 5).

\section{(2) Reservoir space}

The reservoir space consists of primary pores, mixed pores, and secondary pores and gaps. Primary pores include the remaining intergranular pores after compaction and cementation and micropores in clay mineral matrices making up the main pore type (Fig. 6e, f, g). Expansion of pores by dissolution is the main kind of mixed pores (Fig. 6h). There are various kinds of secondary pores and gaps containing dissolution pores in particles and cements (Fig. 6k, 1), moldic pores (Fig. 6i), intergranular micropores of kaolinite (Fig. 6m, n, o and p), microfractures and diagenetic contraction fractures. As one kind of gravity flow deposits, turbidite is characterized by a large amount of matrix which contains significant amounts of primary micropores. During the process of diagenetic evolution, additional intergranular micropores are developed due to the transformation from feldspar to kaolinite (Bjørlykke 2014; Giles and de Boer 1990) (Fig. 6m, n, o). The large proportion of micropores results in much lower permeability of reservoirs than that of other reservoirs with the same porosity (Yuan et al. 2013, 2015; Cao et al. 2014). So middle and high porosity low permeability reservoirs are common.

\section{(3) The characteristics of pore throat structure}

Using mercury injection data, we classify pore-throat structures according to the parameters of displacement pressure $\left(P_{\mathrm{d}}\right)$ 

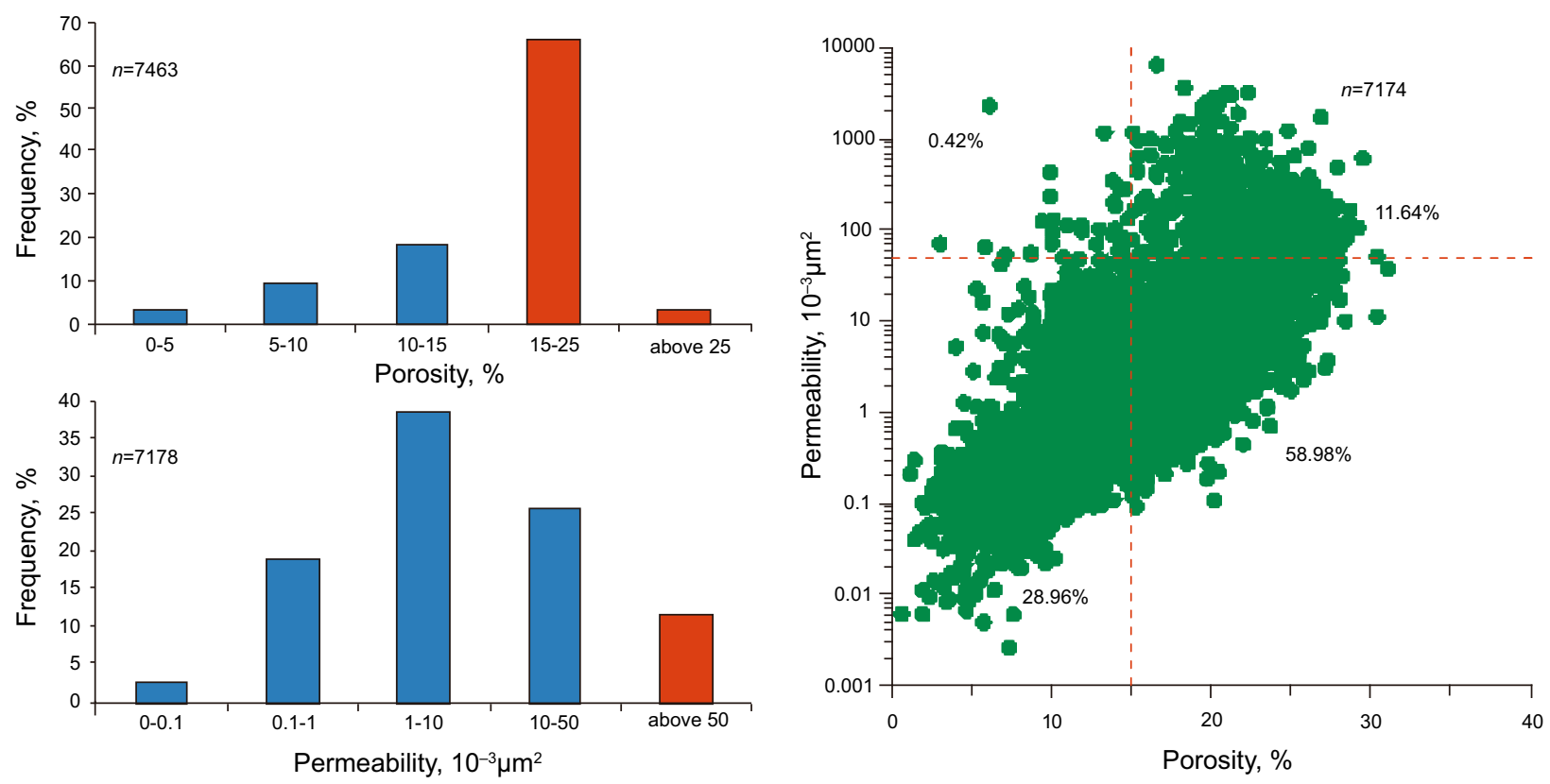

Fig. 5 Plots illustrating the porosity and permeability distribution of the low permeability $\mathrm{Es}_{3}^{\mathrm{z}}$ turbidite reservoirs

and median capillary pressure $\left(P_{50}\right)$ (Wang et al. 2014a). First, reservoirs are classified into six types according to displacement pressure $\left(P_{\mathrm{d}}\right)$ IA $\left(P_{\mathrm{d}} \leq 0.05 \mathrm{MPa}\right)$, IB $(0.05-0.1 \mathrm{MPa}$ $\left.P_{\mathrm{d}}\right)$, IIA $\left(0.1-0.5 \mathrm{MPa} P_{\mathrm{d}}\right)$, IIB $\left(0.5-2 \mathrm{MPa} P_{\mathrm{d}}\right)$, IIIA (2-5 MPa $\left.P_{\mathrm{d}}\right)$, and IIIB $\left(P_{\mathrm{d}}>5 \mathrm{MPa}\right)$. Second, each type is further divided into six units according to median capillary pressure $\left(P_{50}\right) P_{50} \leq 0.3 \mathrm{MPa}, 0.3-1.5 \mathrm{MPa} P_{50}, 1.5-5 \mathrm{MPa}$ $P_{50}, 5-20 \mathrm{MPa} P_{50}, 20-40 \mathrm{MPa} P_{50}, P_{50}>40 \mathrm{MPa}$. If the $P_{50}$ datum of a sample is not in accordance with the overall characteristics of a unit, then the sample is assigned to the lower unit (Wang et al. 2014a). We divide the $\mathrm{Es}_{3}^{\mathrm{z}}$ turbidite reservoirs in the Dongying Sag into three broad types and six types. Then we correlate $K / \Phi$ with $K$ for each type of reservoir (Fig. 7). So, we can determine the ranges of permeability and the ratio of permeability to porosity corresponding to various types of reservoirs (Table 1). Reservoirs with different kinds of pore throat structures have the same power function relationship between $K / \Phi$ and $K$. This reflects that the permeability of low permeability reservoirs is controlled by pore throat structures. However, different kinds of reservoirs have different ranges of permeability (Fig. 7). Good pore throat structures are characterized by lower $P_{\mathrm{d}}$ and $P_{50}$, as well as higher $K / \Phi$ and $K$ values; poor pore throat structures are characterized by higher $P_{\mathrm{d}}$ and $P_{50}$ and lower $K / \Phi$ and $K$ values.

\subsubsection{Diagenesis features}

\section{(1) Diagenetic events}

The major diagenetic events in the research area include compaction, cementation, replacement, and dissolution.
Fig. 6 Typical diagenesis characteristics and reservoir pore types of the low permeability $\mathrm{Es}_{3}^{\mathrm{z}}$ turbidite reservoirs. a Wangxie 543,

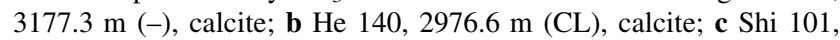
$3259.5 \mathrm{~m}(-)$, quartz overgrowth; d He 135, $3030.87 \mathrm{~m}$ (CL), quartz overgrowth; e Niu 42, $3258.6 \mathrm{~m} \mathrm{(-),} \mathrm{grain} \mathrm{point} \mathrm{contact;} \mathrm{f} \mathrm{He} \mathrm{155,}$ $2987.04 \mathrm{~m} \mathrm{(-),} \mathrm{primary} \mathrm{pore;} \mathrm{g} \mathrm{Shi} \mathrm{101,} 3258.6 \mathrm{~m}$ (SEM), primary pore; h Hao 7, $2961.1 \mathrm{~m} \mathrm{(-),} \mathrm{dissolution} \mathrm{expanding} \mathrm{pore;} \mathrm{i} \mathrm{Wangxie}$

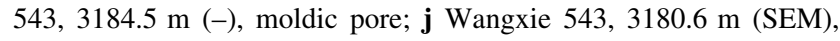
feldspar dissolution pore; $\mathbf{k}$ Dongke 1, $3333.65 \mathrm{~m}(-)$, ankerite dissolution pore; I Dongke 1, $3333.65 \mathrm{~m}$ (SEM), ankerite dissolution pore; $\mathbf{m}$ Nan 1, 3403.35 m (-), kaolinite replaces feldspar; $\mathbf{n}$ He 155, 2987.04 m (SEM), kaolinite replaces feldspar; o Hao 5, $3142.01 \mathrm{~m}$ (SEM), kaolinite filling pore; p Wangxie 543, $3180.6 \mathrm{~m}$ (SEM), kaolinite part illitization. $Q$ quartz; $F$ feldspar; $R$ rock fragments; $M$ matrix; $Q a$ quartz overgrowth; $K a$ kaolinite; $I l$ illite; $C c$ carbonate cement; $F D$ feldspar dissolution; $C D$ carbonate dissolution; $P P$ primary pore; (-) plane-polarized light; $C L$ cathodoluminescence; SEM scanning electron microscope

Grains are arranged mainly by point contacts and pointline contacts, reflecting moderate compaction (Fig. 6e). The reservoirs are mainly carbonate cemented. The first groups of carbonate cements are calcite and ferroan calcite. Calcite and ferroan calcite always occur in the form of basal cementation (Fig. 6a) or porous cementation (Fig. 6b). The second groups of carbonate cements are dolomite, ankerite, and siderite. As revealed from our observations, dolomite, ankerite, and siderite always develop euhedral crystals (Fig. 6k). Quartz overgrowth is the main kind of siliceous cementation (Fig. 6c, d). Two phases of quartz overgrowths can be identified by cathodoluminescence microscopy. The first phase of quartz overgrowth is dark black and the second phase is brown as also described by Lander et al. (2008) and 

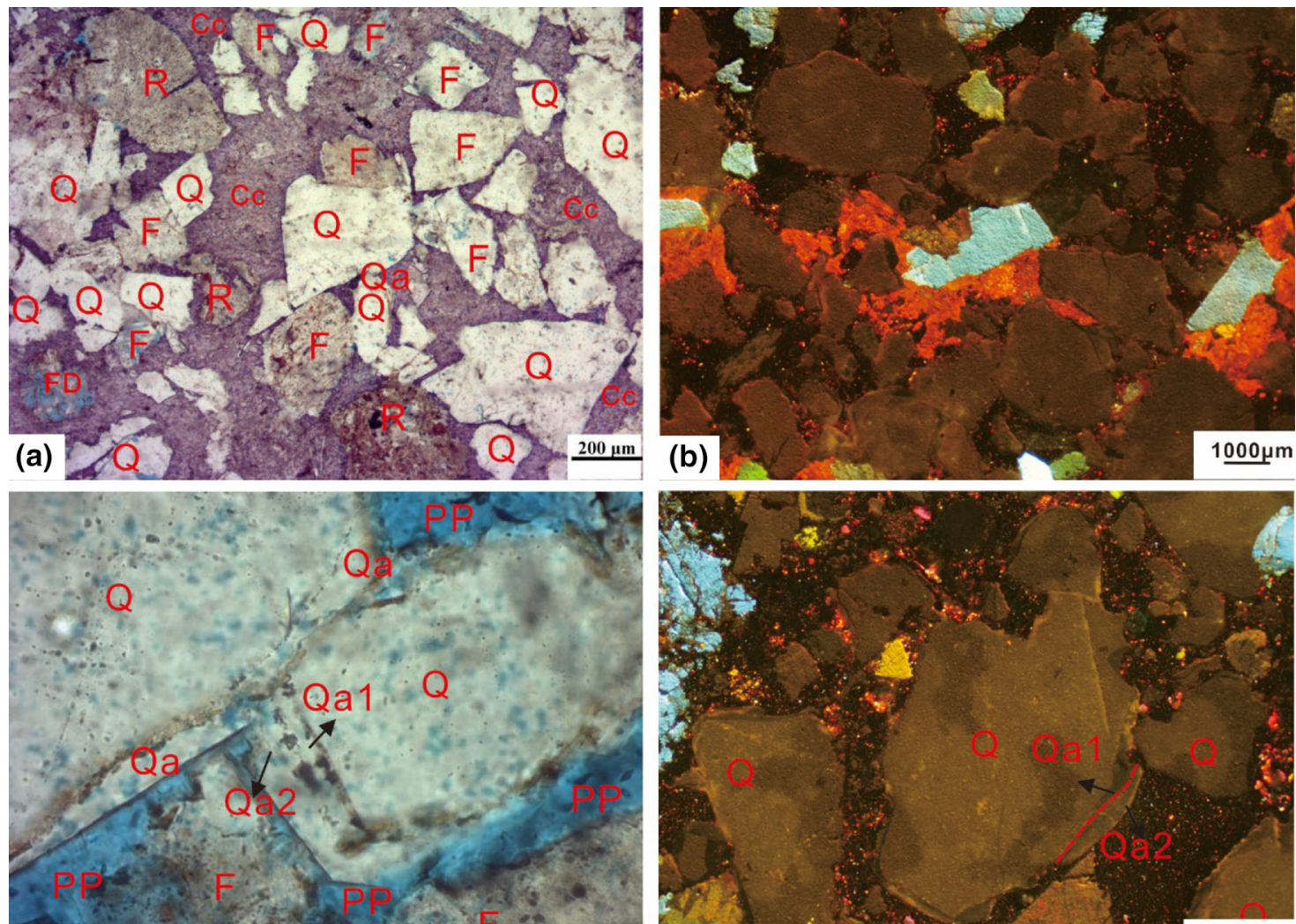

(c)

$15 \mu \mathrm{m}$
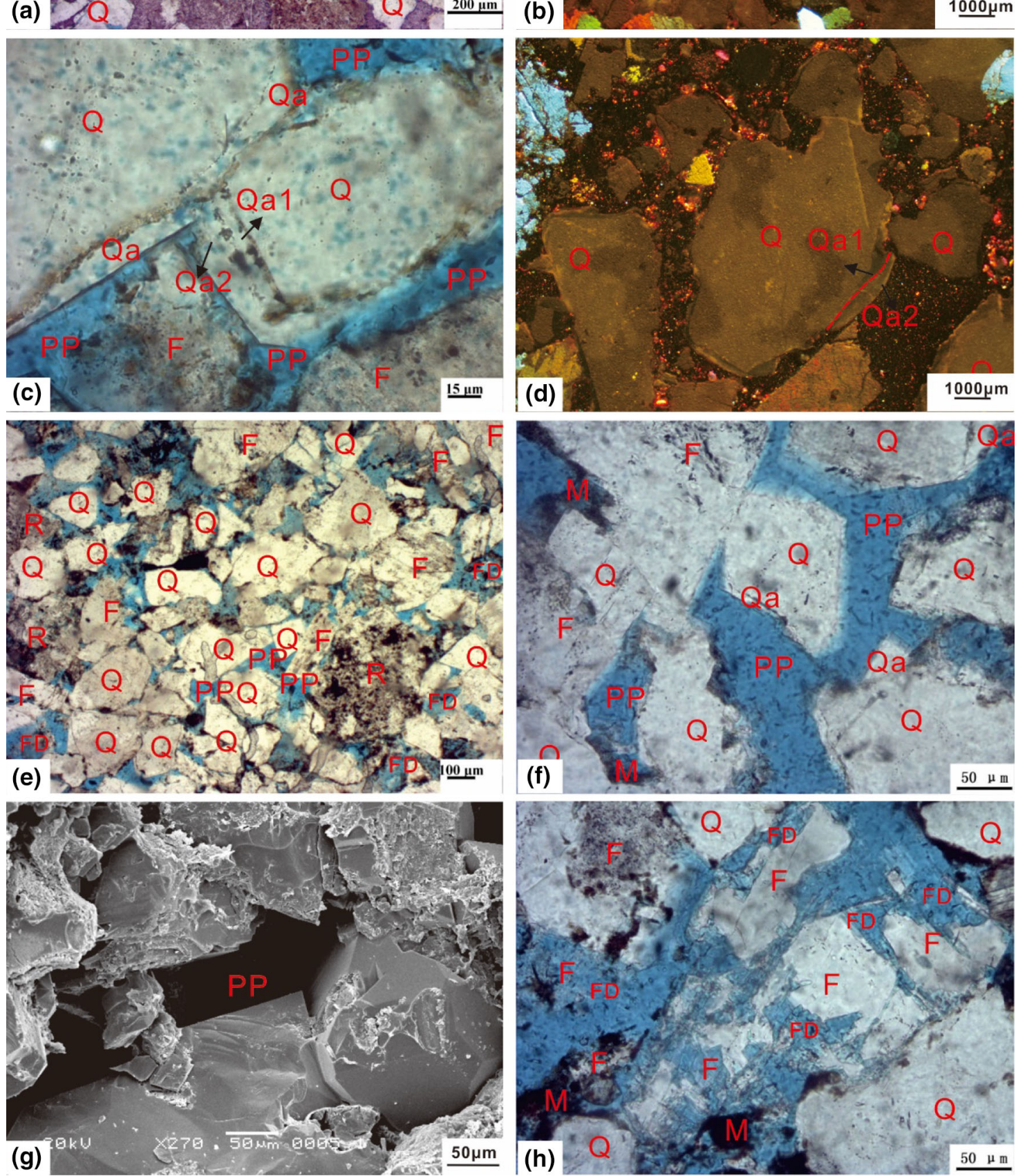

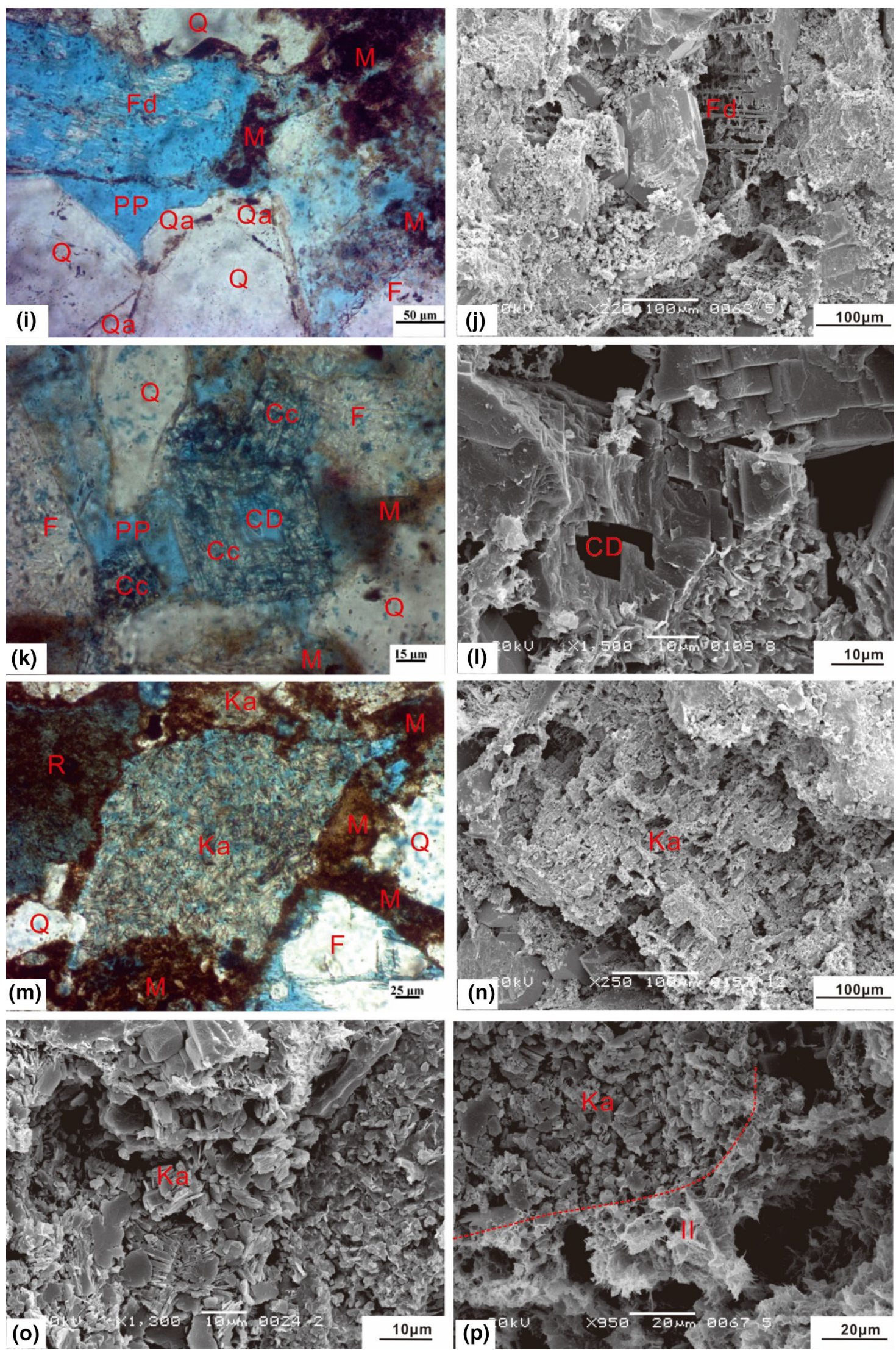

Fig. 6 continued 

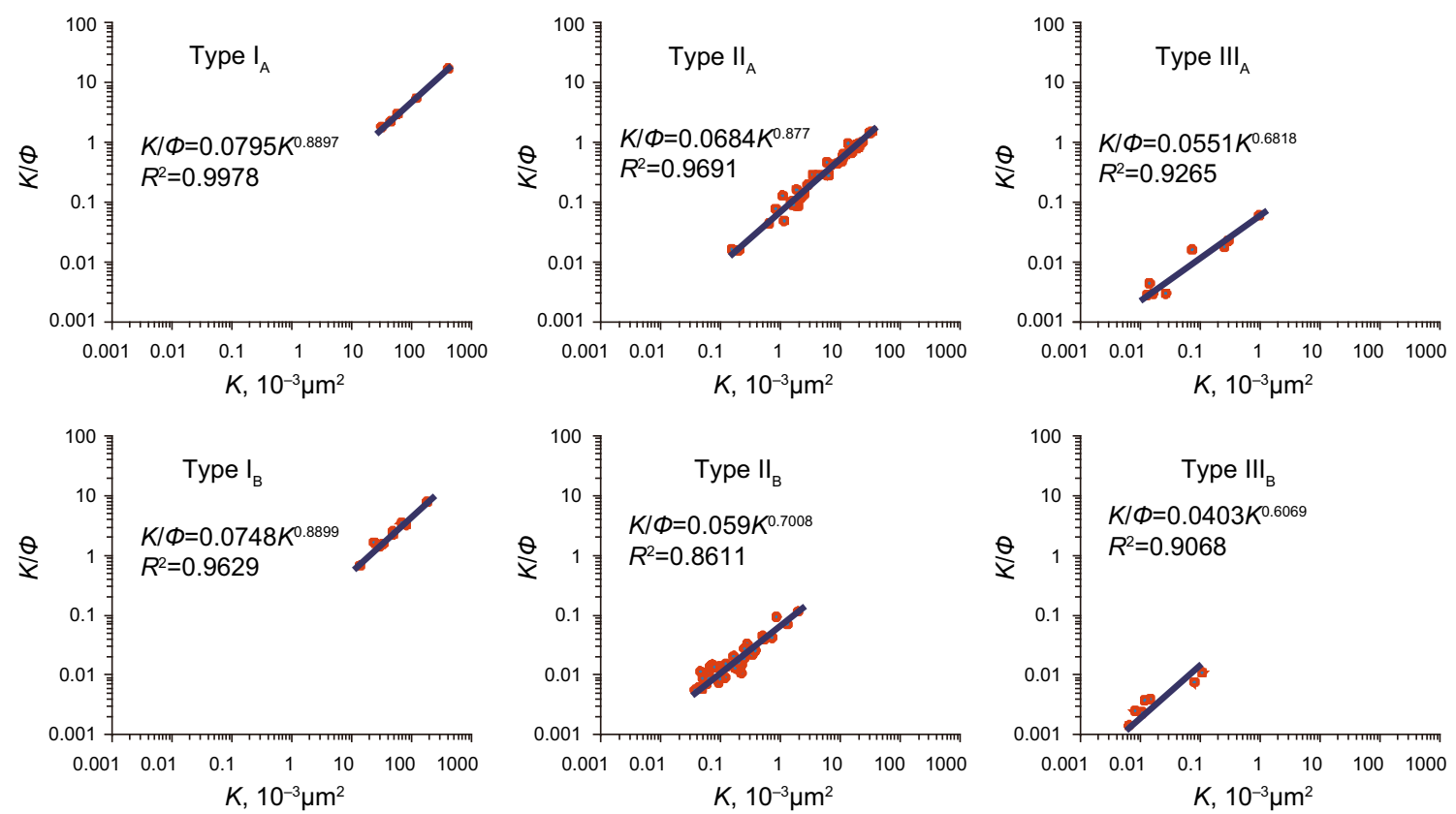

Fig. 7 Pore-throat structure types and their porosity-permeability relationships of the low permeability Es ${ }_{3}^{\mathrm{z}}$ turbidite reservoirs

Table 1 Ranges of $K$ and $K / \Phi$ of different pore structures of the low permeability $\mathrm{Es}_{3}^{\mathrm{z}}$ turbidite reservoirs

\begin{tabular}{llllr}
\hline Type of pore-throat structure & $K, 10^{-3} \mu \mathrm{m}^{2}$ & $K / \Phi$ & $P_{\mathrm{d}}, \mathrm{MPa}$ & $P_{50}, \mathrm{MPa}$ \\
\hline IA & $>30.6$ & $>1.52$ & $0.02-0.05$ & $0.26-0.61$ \\
IB & $13.9-183.34$ & $0.68-7.85$ & $0.06-1$ & $0.16-1.26$ \\
IIA & $0.15-34.3$ & $0.016-1.54$ & $0.15-0.5$ & $0.48-4.41$ \\
IIB & $0.037-1.95$ & $0.0056-0.12$ & $0.15-2$ & $2.84-22.35$ \\
IIIA & $0.013-0.96$ & $0.0027-0.058$ & $0.8-4$ & $17.36-74.12$ \\
IIIB & $<0.11$ & $<0.011$ & $3-8$ & $47.8-73.53$ \\
\hline
\end{tabular}

Tournier et al. (2010). Kaolinite is the most important kind of clay mineral (Fig. 6m, n, o). Kaolinite mainly occurs as euhedral booklets and vermicular aggregates with abundant intercrystalline microporosity. The margin of kaolinite is fibrous as a result of illitization (Fig. 6p). The dissolution of feldspar (Fig. 6h, i, j), lithic fragments, carbonate cements, and other minerals which are unstable in the acid environment can form honeycomb-shaped dissolution expanding pores with curved outlines (Fig. 6k, 1). Besides this, quartz and quartz overgrowths have been slightly dissolved. Replacement between carbonate cements (Fig. 6d), between carbonate cements and detrital particles (Fig. 6b), between kaolinite and feldspar (Fig. 6c) all occurred. Replacement between carbonate cements mainly results in dolomite replacing calcite, ferroan calcite replacing calcite, ankerite replacing calcite, and ankerite replacing ferroan calcite.

\section{(2) Paragenesis of diagenetic minerals}

On the basis of previous studies (Jiang et al. 2003), the analysis of the fluorescence color of hydrocarbon inclusions and thermometry analysis of aqueous inclusions which were captured at the same time as hydrocarbon inclusions can identify two periods of hydrocarbon accumulation. The first period of hydrocarbon accumulation is from 27.5 to $24.6 \mathrm{Ma}$, and the second period is from 13.8 Ma until now. From observations using cathodoluminescence and polarizing microscopy, two phases of quartz overgrowths can be recognized. There are some hydrocarbon inclusions and oil absorption on clay minerals located in the boundaries between quartz grains and overgrowth rims (Fig. 8i, k) as also described by Girard et al. (2002) and Higgs et al. (2007). The color of those organic materials is orange to yellow in fluorescence microscopy which reflects the low maturity of hydrocarbon (Liu et al. 2014c; Chen 2014). It can be inferred that the first phase of quartz overgrowths formed after the early period hydrocarbon filling. The homogenization temperature of the aqueous inclusions in the first phase of quartz overgrowths ranges from 98 to $118{ }^{\circ} \mathrm{C}$ with an average of $106{ }^{\circ} \mathrm{C}$ (Fig. 9). The color of hydrocarbon inclusions in the second phase of quartz overgrowths is blue and white under the fluorescence microscope which reflects a high hydrocarbon 

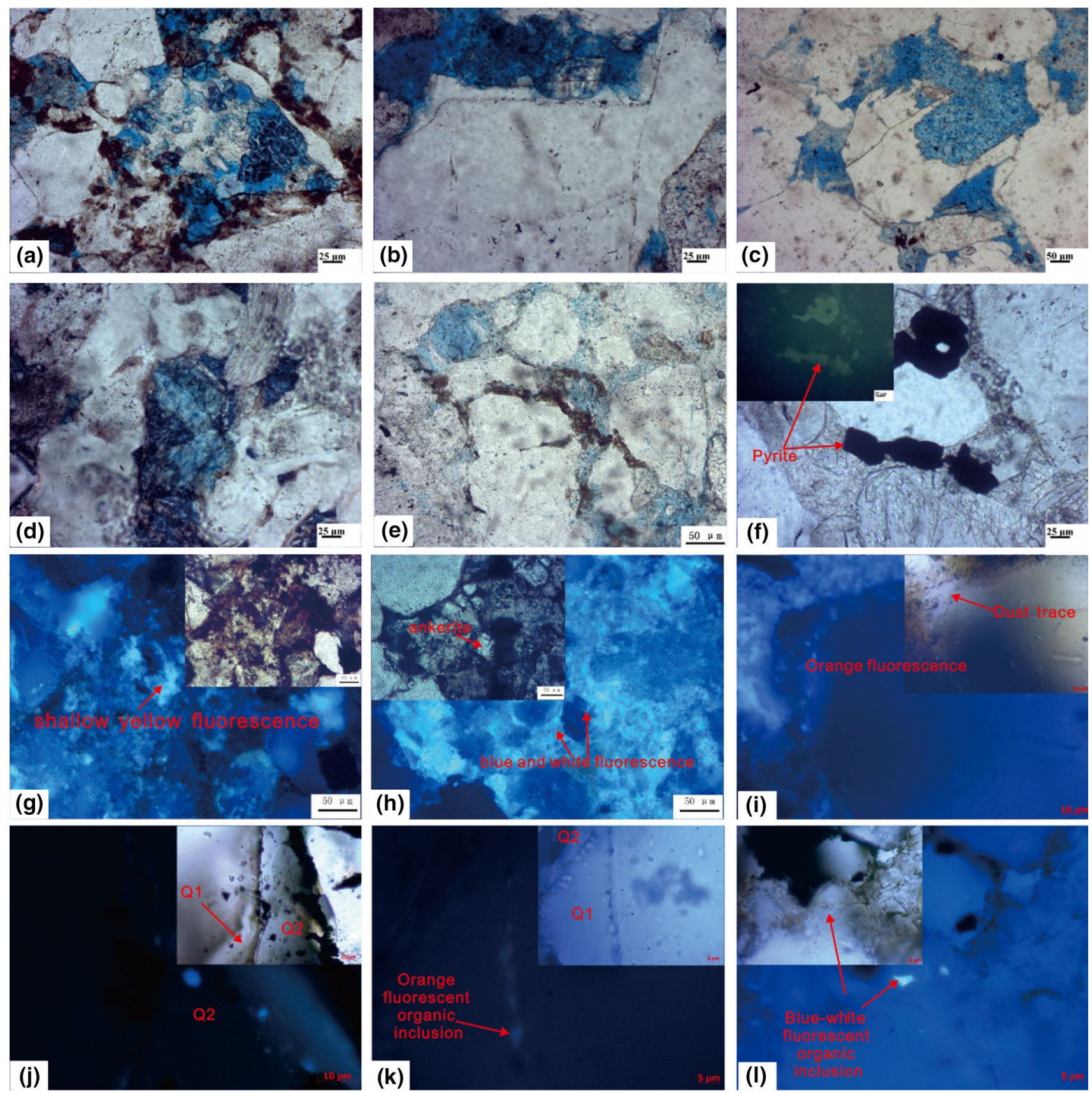

Fig. 8 Optical microscope micrographs illustrating the texture and nature of the paragenesis of diagenetic minerals of the low permeability Es ${ }_{3}^{z}$ turbidite reservoirs. a Niu 24, $3175.61 \mathrm{~m}(-)$, feldspar dissolution pore filled by ankerite; b Niu 30, $2871.85 \mathrm{~m}(-)$, ankerite replaced quartz overgrowth; c Niu 83, 3199.83 m (-), feldspar dissolution pore filled by kaolinite; d Niu 30, $2891.62 \mathrm{~m}$ (-), ankerite replaced quartz ferroan calcite; e Liang 49, $2836.13 \mathrm{~m}(-)$, siderite growth around a quartz particle; f Niu 128, $3059.55 \mathrm{~m}$ (-), pyrite replaced carbonate cements; $\mathbf{g}$ Niu 43, $3266.80 \mathrm{~m}$ (FL), first period oil filling after feldspar dissolution; h Liang 49, $2838.13 \mathrm{~m}$ (FL), blue in cleavage crack and margin of ankerite; i Shi 101, $3263.9 \mathrm{~m}$ (FL), orange fluorescence in quartz overgrowth dust trace; j Niu 42, $3261.9 \mathrm{~m}$ (FL), blue-white fluorescent organic inclusion in Q2; k Niu 42, 3261.9 m (FL), orange fluorescent organic inclusion in Q1; I Nan 1, $3401.75 \mathrm{~m}$ (FL), blue-white fluorescent organic inclusion in ankerite. - plane-polarized light; $F L$ fluorescence; $Q 1$ Quartz overgrowth in the first phase; $Q 2$ Quartz overgrowth in the second phase

maturity (Fig. 8j) (Chen 2014). It can be concluded that the quartz overgrowths formed after the late period hydrocarbon fill. The homogenization temperature of the aqueous inclusions in the second phase of quartz overgrowths ranges from 120 to $146{ }^{\circ} \mathrm{C}$ with an average of $134{ }^{\circ} \mathrm{C}$ (Fig. 9). Temperatures calculated from the $\mathrm{O}$ isotope ratios in early carbonate cements (dolomite and calcite) range from 66 to $102{ }^{\circ} \mathrm{C}$ (Guo et al. 2014), and temperatures 

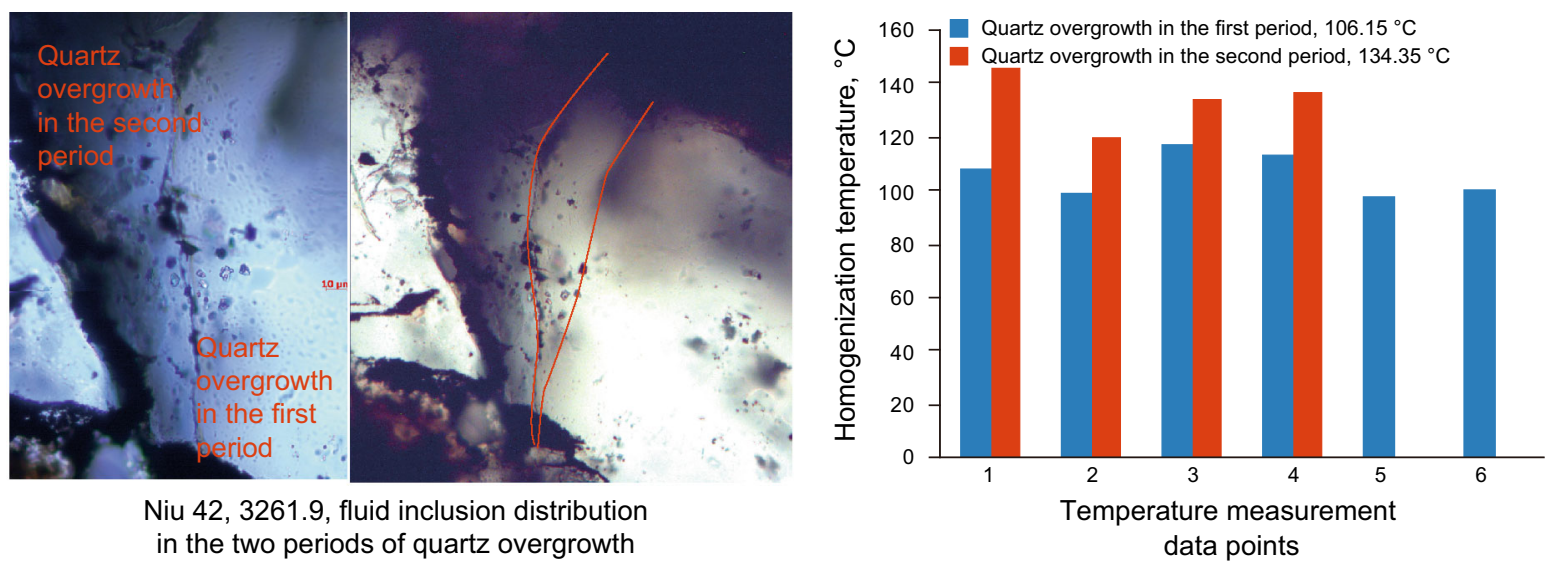

Fig. 9 Fluid inclusion homogenization temperatures of the two phases of quartz overgrowths of the low permeability $\mathrm{Es}_{3}^{\mathrm{z}}$ turbidite reservoirs

calculated from the isotope ratios in late carbonate cements (ferroan calcite and ankerite) range from 110 to $147{ }^{\circ} \mathrm{C}$ (Zhang 2012). There are some blue and white color hydrocarbon inclusions in the ankerite under fluorescence microscopy (Fig. 81), and cleavage cracks and the edges of ankerite grains are impregnated by hydrocarbon with bluewhite fluorescence (Fig. 8h) (Wilkinson et al. 2006). We can infer that the ankerite formed at the same time as hydrocarbon charging.

The siderites and some micritic carbonate have grown around the quartz particles without quartz overgrowths (Fig. 8e), showing that siderite cements formed earlier than the quartz overgrowths. The feldspar dissolution pores were filled by ankerite (Fig. 8a), so feldspar dissolution occurred earlier than ankerite cementation. Ankerite cementation occurred later than quartz overgrowth reflected by the replacement relation between ankerite and quartz overgrowth (Fig. 8b). Ankerite replaced ferroan calcite (Fig. 8d), so ankerite cementation occurred later than ferroan calcite. The feldspar dissolution pores were filled by kaolinite (Fig. 8c), so feldspar dissolution took place earlier than kaolinite cementation. Pyrite replaces carbonate cements (Fig. 8f), so pyrite formed later than carbonate cements.

After the analysis of timing and order of hydrocarbon filling and formation of various authigenic minerals, the paragenesis of authigenic minerals was determined. Siderite/ micritic carbonate $\rightarrow$ first dissolution of feldspar $\rightarrow$ the beginning of the first hydrocarbon filling $\rightarrow$ first quartz overgrowth/authigenic kaolinite precipitation $\rightarrow$ the first group of carbonate cementation $\rightarrow$ the end of the first hydrocarbon filling $\rightarrow$ dissolution of quartz/feldspar overgrowth $\rightarrow$ second dissolution of feldspar and carbonate cementation $\rightarrow$ the beginning of the second hydrocarbon filling $\rightarrow$ second quartz overgrowth/authigenic kaolinite precipitation $\rightarrow$ the second group of carbonate cementation/ pyrite cementation. Compaction existed throughout the entire burial and evolutional processes.

According to the burial history and organic evolution history analysis for the reservoirs in the research area, combined with the diagenetic environment implied by authigenic minerals, the reservoir experienced a diagenetic environment evolution from slightly alkaline $\rightarrow$ acid $\rightarrow$ alkaline $\rightarrow$ slightly acidic now. The early slightly alkaline diagenetic environment was controlled by the original sedimentary water from 42 to $38 \mathrm{Ma}$ (Qi et al. 2006). With the increase of burial depth, a larger amount of organic acid was produced from the evolution of organic matter in high-quality source rocks in $\mathrm{Es}_{3}^{\mathrm{x}}$ and $\mathrm{Es}_{4}^{\mathrm{s}}$ (Surdam et al. 1989). The diagenetic pore-water became acidic, which lasted from 38 to $28 \mathrm{Ma}$, and the temperature of reservoirs was from 80 to $120^{\circ} \mathrm{C}$. With further increase in burial depth, organic acid decarboxylation and the alkaline fluid from the gypsum in $\mathrm{Es}_{4}^{\mathrm{x}}$ dominated the diagenetic environment from 28 to $16.4 \mathrm{Ma}$ (Wang 2010). The strata were uplifted by the Dongying Movement, and organic acid was generated again. The diagenetic pore water became acid again from 16.4 to $5 \mathrm{Ma}$. From $5 \mathrm{Ma}$ to now, organic acid was generated from source rock in $\mathrm{Es}_{3}^{\mathrm{z}}$. As a result of this process, the diagenetic pore water is considered to have remained acidic.

\subsection{Porosity-permeability evolution of $\mathrm{Es}_{3}^{\mathrm{z}}$ low- permeability turbidity reservoirs}

Based on the diagenetic features and paragenetic sequences, the porosity and permeability estimation method for the geological history of the reservoirs has been used (Wang et al. 2013a; Cao 2010). According to this method, we can determine the porosity and permeability of the reservoirs in the accumulation period. First, we take the thin sections of reservoir samples as the study object. After the analysis of the paragenetic sequence and diagenetic 
fluid evolution combined with the study of burial history, we determine the geological time and burial depth of diagenetic events. Second, we fit the function of plane porosity and visual reservoir porosity from the analysis of thin sections, and then we can calculate the contributions of different dissolution pores and authigenic minerals to porosity increase or decrease. After the calculation of initial porosity, the evolution of porosity can be estimated with the principle of inversion and back-stripping constraint of the diagenetic paragenetic sequences. Third, the evolution history of actual porosity with geological time or burial depth with different diagenetic characteristics can be established quantitatively combined with the chart of mechanical and thermal compaction correction. Fourth, on the basis of characteristics of pore throat structure, according to the back-stripping constraint result of plane porosity and the principle of equivalent expanding, the pore throat structures of reservoirs can be estimated at the geological time of the main diagenetic events. Finally, according to the relationship between pore throat structure and porosity, the evolution of permeability in geological time can be estimated with the relationships of porosity and permeability in different kinds of pore throat structures. Taking the turbidite reservoir at the Niu107 well at $3025.5 \mathrm{~m}$ as example (Fig. 10), the estimated permeability of $0.31 \times 10^{-3} \mu \mathrm{m}^{2}$ is close to the actual measured permeability of $0.307 \times 10^{-3} \mu \mathrm{m}^{2}$.

On the basis of diagenetic paragenetic sequences and the type and strength of diagenetic events, the reservoir can be divided into four types of diagenetic facies. These are strong compaction - weak dissolution of feldspar-weak cementation of carbonate: Diagenetic facies (A); weak compaction-weak dissolution of feldspar-strong cementation of carbonate: Diagenetic facies (B); weak compaction-strong dissolution of feldspar-weak cementation of carbonate: Diagenetic facies (C); and medium compaction-medium dissolution of feldspar-medium cementation of carbonate: Diagenetic facies (D). Thin sandstones mainly develop diagenetic facies A and diagenetic facies B. Thick sandstones develop diagenetic facies A and $\mathrm{B}$ in the reservoirs adjacent to mudstones, and diagenetic facies $\mathrm{C}$ and $\mathrm{D}$ in the middle of sandstones (McMahon et al. 1992). Typical samples of different kinds of diagenetic facies were selected and their evolution of porosity-permeability were estimated (Fig. 11). The results show that in the early accumulation period, all reservoirs except for reservoirs with diagenetic facies $\mathrm{A}$ have middle-high permeability ranging from $10 \times 10^{-3} \mu \mathrm{m}^{2}$ to $4207 \times 10^{-3} \mu \mathrm{m}^{2}$. In the later accumulation period, all reservoirs except for reservoirs with diagenetic facies $\mathrm{C}$ have low permeability ranging from $0.015 \times 10^{-3} \mu \mathrm{m}^{2}$ to $62 \times 10^{-3} \mu \mathrm{m}^{2}$.

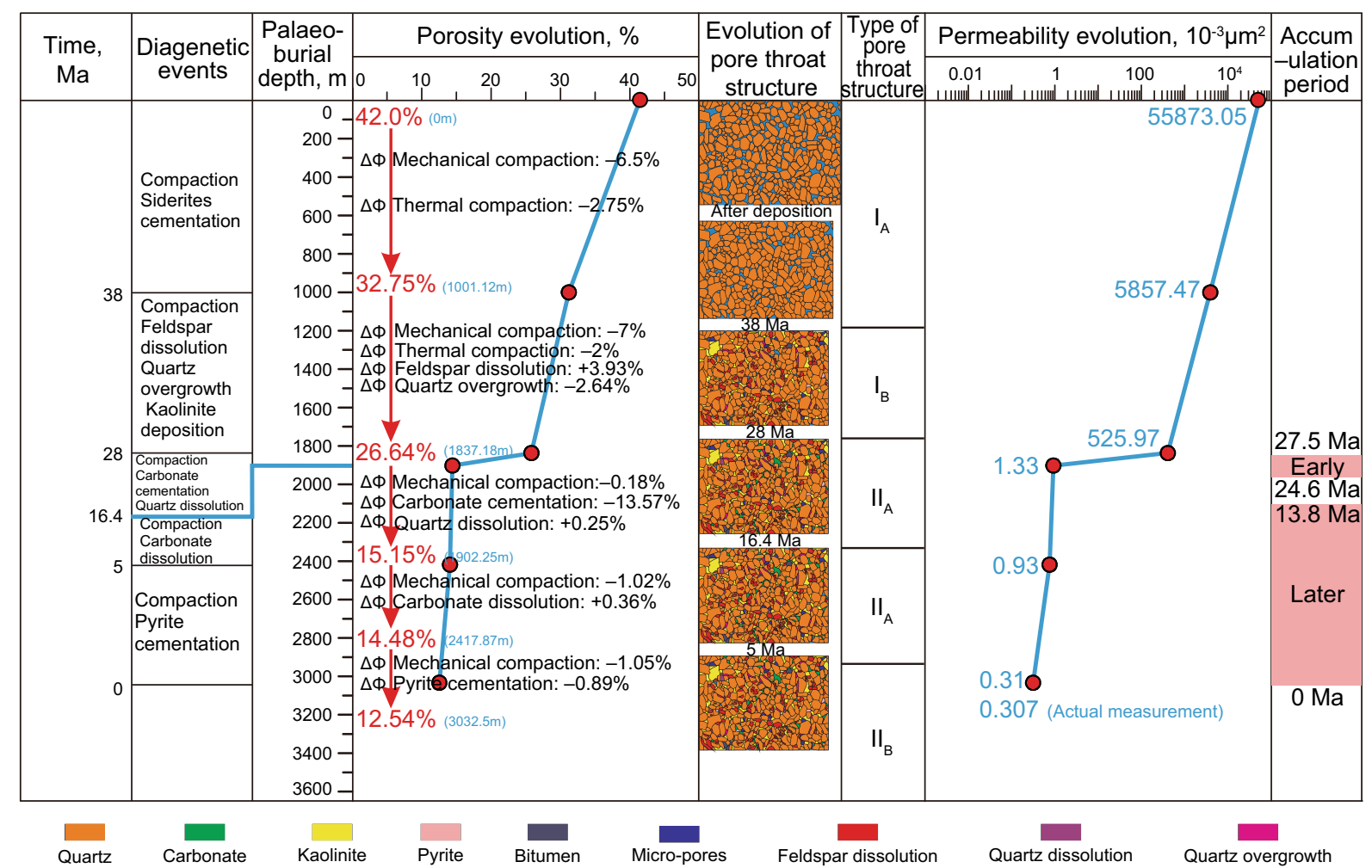

Fig. 10 Porosity-permeability evolution history of the low permeability $\mathrm{Es}_{3}^{\mathrm{z}}$ turbidite reservoirs (Well Niu107, $3032.5 \mathrm{~m}$ ) 


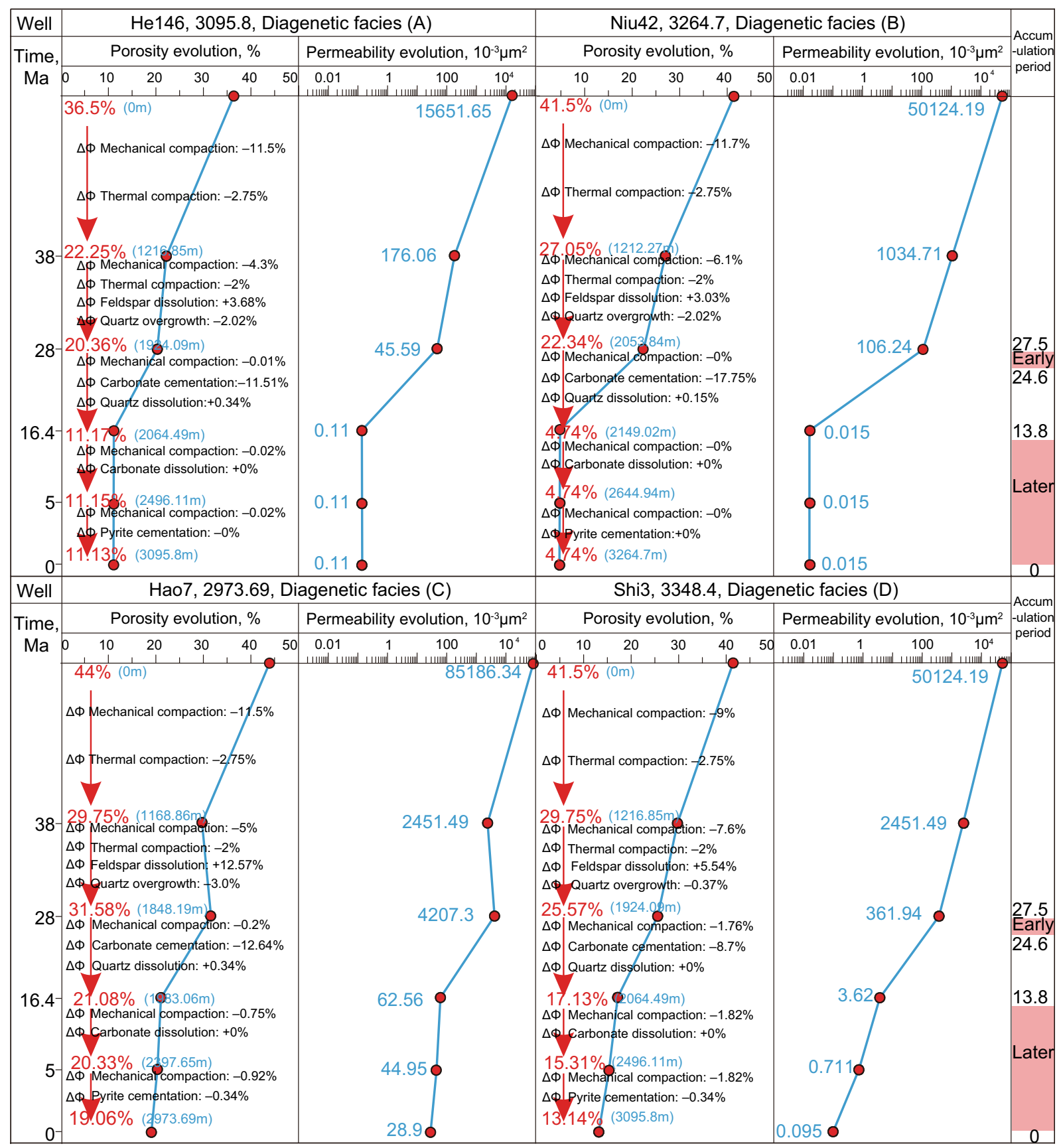

Fig. 11 Porosity-permeability evolution history of different diagenetic facies low permeability $\mathrm{Es}_{3}^{z}$ turbidite reservoirs

\section{Cutoff-values for porosity and permeability of turbidite reservoirs in the accumulation period}

Capillary pressure $(P \mathrm{c})$ is the most important resistance force in hydrophilic reservoir rocks. Only when the dynamic force surpasses the resistance force, can petroleum seep into rocks and form petroleum reservoirs (Hao et al. 2010). We calculated the cutoff-values for porosity and permeability in the accumulation period under the constraint of accumulation dynamics and pore throat structure (Wang et al. 2014a). The method procedure includes: (1) establishing a functional relationship between oil-water interfacial tension and formation temperature; (2) calculating lower limiting values of maximum connected pore-throat radius according to formation temperature and dynamic forces of each reservoir interval; (3) correlating permeability with maximum connected pore-throat radius 
and then obtaining cutoff-values for permeability in the accumulation period; and (4) calculating cutoff-values for porosity on the basis of cutoff-values for permeability according to specific correlations suitable for the type of pore-throat structure (Wang et al. 2014a).

According to the test data of oil-water interfacial tension $(\delta)$ for different formation temperature $(T)$ in the $\mathrm{Es}_{3}$ and $\mathrm{Es}_{4}$ reservoirs in the Dongying Sag, the functional relationship can be written as (Wang et al. 2014a):

$\delta=40.5 \times T^{-0.149}, R^{2}=0.65$

This equation could be used to calculate the oil-water interfacial tension at any given formation temperature. For example, for a formation temperature of $125^{\circ} \mathrm{C}$ which is close to the actual formation temperature of $\mathrm{Es}_{3}^{\mathrm{Z}}$ in the research area, the calculated oil-water interfacial tension is $19.7 \mathrm{mN} / \mathrm{m}$. For a fixed critical accumulation dynamic value $P_{\mathrm{f}}$, we can get cutoffs of maximum connected pore throat radius using equation $r_{0}=2 \delta \cos \theta / P_{\mathrm{f}}$ when the wetting contact angle of oil-water is $0^{\circ}$ and interfacial tension at $125{ }^{\circ} \mathrm{C}$ is $19.7 \mathrm{mN} / \mathrm{m}$ (Table 2).

Establishing a correlation between permeability and maximum connected pore-throat radius using mercury injection data (Fig. 12), we find that there is a good exponential relationship between permeability and the maximum connected pore-throat radius as:

$K=0.3927 \times r_{0}^{1.7992}, R^{2}=0.8275$,

where $K$ is the permeability, $10^{-3} \mu \mathrm{m}^{2} ; r_{0}$ is the maximum connected pore-throat radius, $\mu \mathrm{m}$.

Substituting the limiting value of the maximum connected pore-throat radius under different critical accumulation dynamics into Eq. (2), a series of cutoff-values for permeability in the accumulation period can be obtained at $125^{\circ} \mathrm{C}$ (Table 2).

On the basis of the classification of pore-throat structures, according to the functional relationships between $K$ and $K / \Phi$ of different pore-throat structures as well as their variation ranges (Fig. 4, Table 1), we calculated cutoff-values for porosity according to variation ranges of permeability in Table 1 and regarded those values as cutoff-values for porosity in the accumulation period for the corresponding type of pore-throat structures under different critical accumulation dynamics. With the same method, we can calculate the cutoff-values for porosity and permeability in the accumulation period for the corresponding type of pore-throat structures under different critical accumulation dynamics at different formation temperatures (Fig. 13).

\section{Control on the oil-bearing potential of a reservoir by the relationship between permeability and dynamics in the accumulation period}

\subsection{Accumulation dynamics estimation}

The turbidite reservoirs are located in overpressured formations of the Dongying Sag. Overpressure is the main dynamic controlling hydrocarbon accumulation (Zhuo et al. 2006; Sui et al. 2008; Gao et al. 2010). Disequilibrium stresses under a high subsidence rate or rapid burial and hydrocarbon generation are the two possible overpressure generating mechanisms in sedimentary basins (Bao et al. 2007; Bloch et al. 2002; Taylor et al. 2010). By means of fluid inclusion PVT simulation, the minimum fluid pressure in the hydrocarbon accumulation period can be obtained. According to basin modeling techniques, fluid pressure resulting from disequilibrium compaction can be determined (the balance pressure between sandstones and mudstones). The differences between those two pressures are the increased minimum fluid pressure of hydrocarbon generation. For an isolated lenticular sand body without faults, fluid pressures generated by disequilibrium compaction would transfer from mudstones to sandstones to reach a balance of fluid pressure (Cai et al. 2009). So the fluid pressure generated by hydrocarbon generation is the main accumulation dynamic. For a sand body with faults developed, the surplus pressure which is the difference between fluid pressure and hydrostatic pressure will result in fluid migration through the faults which is the main accumulation dynamic (Zhuo et al. 2006; Cai et al. 2009). According to the estimations of the accumulation dynamics of reservoirs in the research area (Table 3), in the early accumulation period the fluid pressure increase by hydrocarbon generation is $1.4-11.3 \mathrm{MPa}$ with an average of $5.14 \mathrm{MPa}$, and the surplus pressure is $1.8-12.6 \mathrm{MPa}$ with an average of $6.3 \mathrm{MPa}$. In the late accumulation period the fluid pressure increased by hydrocarbon generation is 0.7-12.7 MPa with an average of 5.4 MPa, and the surplus pressure is $1.3-16.2 \mathrm{MPa}$ with an average of 6.6 MPa. The accumulation dynamics in the later accumulation period are stronger than those in the early accumulation period.

\subsection{Coupling of dynamics and permeability in the hydrocarbon accumulation period}

The estimation of the permeability of reservoirs with different diagenetic facies indicated that the permeability of the 
Table 2 Cutoff-values for porosity and permeability of the low permeability $\mathrm{Es}_{3}^{\mathrm{z}}$ turbidite reservoirs under the constraint of the accumulation dynamics and pore throat structure and at $125{ }^{\circ} \mathrm{C}$ formation temperature

\begin{tabular}{|c|c|c|c|c|c|c|c|c|}
\hline \multirow{2}{*}{$\begin{array}{l}\text { Accumulation } \\
\text { dynamics } P_{\mathrm{f}}, \mathrm{MPa}\end{array}$} & \multirow{2}{*}{$\begin{array}{l}\text { Maximum connected pore-throat } \\
\text { radius } r_{0}, \mu \mathrm{m}\end{array}$} & \multirow[t]{2}{*}{$K_{\text {cutoff }}, 10^{-3} \mu \mathrm{m}^{2}$} & \multicolumn{6}{|c|}{$\Phi_{\text {cutoff }}, \%$} \\
\hline & & & $\Phi_{\mathrm{IA}}$ & $\Phi_{\mathrm{IB}}$ & $\Phi_{\text {IIA }}$ & $\Phi_{\mathrm{IIB}}$ & $\Phi_{\mathrm{IIIA}}$ & $\Phi_{\mathrm{IIIB}}$ \\
\hline 0.01 & 48.45 & 422.82 & 24.04 & - & - & - & - & - \\
\hline 0.02 & 24.22 & 121.49 & 21.62 & 22.68 & - & - & - & - \\
\hline 0.024 & 20.19 & 87.51 & 21.02 & 21.87 & - & - & - & - \\
\hline 0.026 & 18.63 & 75.78 & 20.77 & 21.53 & - & - & - & - \\
\hline 0.03 & 16.15 & 58.58 & 20.32 & 20.93 & - & - & - & - \\
\hline 0.04 & 12.11 & 34.91 & 19.44 & 19.77 & 22.63 & - & - & - \\
\hline 0.05 & 9.69 & 23.37 & - & 18.91 & 21.54 & - & - & - \\
\hline 0.055 & 8.81 & 19.68 & - & 18.56 & 21.09 & - & - & - \\
\hline 0.06 & 8.07 & 16.83 & - & 18.24 & 20.69 & - & - & - \\
\hline 0.065 & 7.45 & 14.57 & - & 17.96 & 20.33 & - & - & - \\
\hline 0.07 & 6.92 & 12.75 & - & - & 20.0 & - & - & - \\
\hline 0.075 & 6.46 & 11.27 & - & - & 19.69 & - & - & - \\
\hline 0.08 & 6.06 & 10.03 & - & - & 19.41 & - & - & - \\
\hline 0.09 & 5.38 & 8.12 & - & - & 18.91 & - & - & - \\
\hline 0.1 & 4.84 & 6.71 & - & - & 18.48 & - & - & - \\
\hline 0.2 & 2.42 & 1.93 & - & - & 15.85 & 20.63 & - & - \\
\hline 0.3 & 1.62 & 0.93 & - & - & 14.49 & 16.59 & 17.74 & - \\
\hline 0.32 & 1.51 & 0.83 & - & - & 14.29 & 16.02 & 17.09 & - \\
\hline 0.4 & 1.21 & 0.55 & - & - & 13.60 & 14.21 & 15.04 & - \\
\hline 0.49 & 1 & 0.39 & - & - & 13.0 & 12.74 & 13.39 & - \\
\hline 0.5 & 0.97 & 0.37 & - & - & 12.94 & 12.60 & 13.24 & - \\
\hline 0.7 & 0.69 & 0.2 & - & - & 12.01 & 10.51 & 10.92 & - \\
\hline 0.9 & 0.54 & 0.13 & - & - & - & 9.18 & 9.46 & - \\
\hline 1 & 0.48 & 0.11 & - & - & - & 8.68 & 8.90 & 10.29 \\
\hline 1.2 & 0.4 & 0.077 & - & - & - & 7.86 & 8.02 & 9.05 \\
\hline 1.4 & 0.35 & 0.058 & - & - & - & 7.24 & 7.34 & 8.11 \\
\hline 1.5 & 0.32 & 0.051 & - & - & - & 6.97 & 7.06 & 7.73 \\
\hline 1.6 & 0.3 & 0.046 & - & - & - & 6.74 & 6.80 & 7.38 \\
\hline 2 & 0.24 & 0.031 & - & - & - & - & 5.99 & 6.30 \\
\hline 2.2 & 0.22 & 0.026 & - & - & - & - & 5.67 & 5.89 \\
\hline 2.4 & 0.2 & 0.022 & - & - & - & - & 5.39 & 5.54 \\
\hline 2.5 & 0.19 & 0.021 & - & - & - & - & 5.27 & 5.38 \\
\hline 3 & 0.16 & 0.015 & - & - & - & - & 4.75 & 4.73 \\
\hline 3.2 & 0.15 & 0.013 & - & - & - & - & 4.57 & 4.52 \\
\hline 3.4 & 0.14 & 0.012 & - & - & - & - & - & 4.33 \\
\hline 3.6 & 0.14 & 0.011 & - & - & - & - & - & 4.16 \\
\hline 4 & 0.12 & 0.009 & - & - & - & - & - & 3.86 \\
\hline 6 & 0.08 & 0.004 & - & - & - & - & - & 2. 90 \\
\hline 8 & 0.06 & 0.003 & - & - & - & - & - & 2.37 \\
\hline 10 & 0.05 & 0.002 & - & - & - & - & - & 2.02 \\
\hline
\end{tabular}

reservoir ranged from $10 \times 10^{-3} \mu^{2}$ to $4207 \times$ $10^{-3} \mu \mathrm{m}^{2}$ in the early accumulation period. When there is no fault development in the sand body, the fluid pressure increased by hydrocarbon generation is the main accumulation dynamic. The fluid pressure increased by hydrocarbon generation is $1.4-11.3 \mathrm{MPa}$ with an average value of 5.1 MPa. Using the minimum accumulation dynamics of 1.4 $\mathrm{MPa}$, the maximum cutoff-value for permeability in the accumulation period at a formation temperature of $125^{\circ} \mathrm{C}$ was calculated to be $0.058 \times 10^{-3}{\mu \mathrm{m}^{2}}^{2}$. The permeability of 


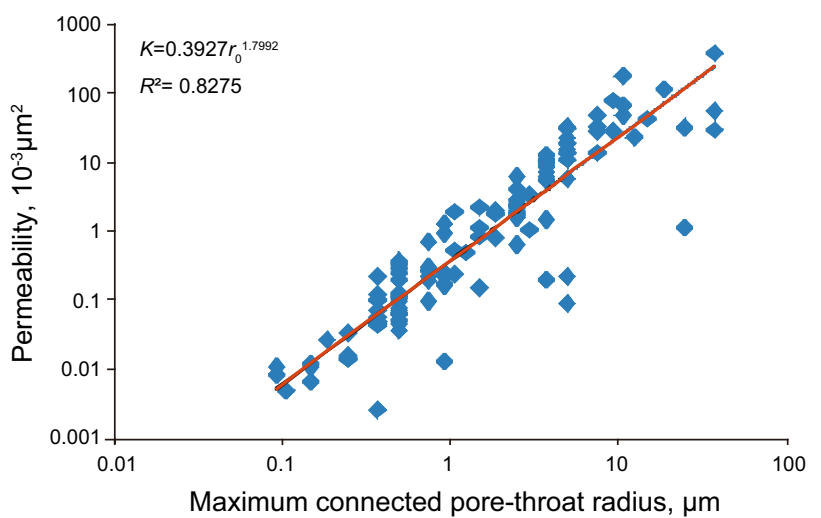

Fig. 12 The relationship between permeability and maximum connected pore-throat radius of the low permeability $\mathrm{Es}_{3}^{\mathrm{z}}$ turbidite reservoirs

the reservoir in the early accumulation period was much higher than this cutoff-value, so all the studied reservoirs could accumulate hydrocarbon. When there is fault development in the sand body, the surplus pressure is the main accumulation dynamic. The surplus pressure is 1.8-12.6 MPa with an average of 6.3 MPa. Using the minimum accumulation dynamics of $1.8 \mathrm{MPa}$, the maximum cutoff-value for permeability in the accumulation period at a formation temperature of $125{ }^{\circ} \mathrm{C}$ was calculated to be $0.037 \times 10^{-3} \mu \mathrm{m}^{2}$. The permeability of the reservoirs in the early accumulation period was much higher than this cutoffvalue, so all the studied reservoirs could accumulate hydrocarbon.

In the later accumulation period the permeability had been reduced and was in the range of $0.015 \times 10^{-3} \mu \mathrm{m}^{2}$ to $62 \times 10^{-3} \mu \mathrm{m}^{2}$. The fluid pressure increased by hydrocarbon generation was $0.7 \mathrm{MPa}$ to $12.7 \mathrm{MPa}$ with an average of $5.4 \mathrm{MPa}$ in the late accumulation period. Using the minimum accumulation dynamics of $0.7 \mathrm{MPa}$, the maximum cutoff-value for permeability in the accumulation period at a formation temperature of $125^{\circ} \mathrm{C}$ was calculated to be $0.203 \times 10^{-3} \mu \mathrm{m}^{2}$. Using the maximum accumulation dynamics of $12.7 \mathrm{MPa}$, the minimum cutoffvalue for permeability in the accumulation period at a formation temperature of $125^{\circ} \mathrm{C}$ is calculated to be $0.001 \times 10^{-3} \mu \mathrm{m}^{2}$. So, at the high level of accumulation dynamics hydrocarbon can accumulate in all studied reservoirs. Reservoirs with diagenetic facies A and diagenetic facies $\mathrm{B}$ do not develop accumulation conditions at the low level of accumulation dynamics, because the permeability of reservoirs with diagenetic facies A and diagenetic facies B is lower than the maximum cutoff value. The surplus pressure is $1.3-16.2 \mathrm{MPa}$ with an average of 6.6 MPa. Using the minimum accumulation dynamics 1.3 $\mathrm{MPa}$, the maximum cutoff-value for permeability in the accumulation period at a formation temperature of $125^{\circ} \mathrm{C}$ was calculated to be $0.066 \times 10^{-3} \mu \mathrm{m}^{2}$. Using the maximum accumulation dynamics $16.2 \mathrm{MPa}$, the minimum cutoff-value for permeability in the accumulation period at a formation temperature of $125{ }^{\circ} \mathrm{C}$ was calculated to be $0.0007 \times 10^{-3} \mu \mathrm{m}^{2}$. So, different kinds of reservoirs can all accumulate hydrocarbon with high accumulation dynamics. Reservoirs with diagenetic facies A and diagenetic facies B do not develop accumulation conditions at the low level of accumulation dynamics.

\subsection{Distribution of hydrocarbon resources}

The $\mathrm{Es}_{3}^{\mathrm{Z}}$ source rocks are not fully mature, because the burial depth of the $\mathrm{Es}_{3}^{\mathrm{z}}$ turbidite reservoirs ranges from 2500 to $3500 \mathrm{~m}$. Oil-source correlation analysis indicated that the oil of the low permeability turbidite reservoirs in the early accumulation period comes from source rocks in $\mathrm{Es}_{3}^{\mathrm{x}}$ and $\mathrm{Es}_{4}^{\mathrm{s}}$ (Cai 2009). The source rocks are overlain by

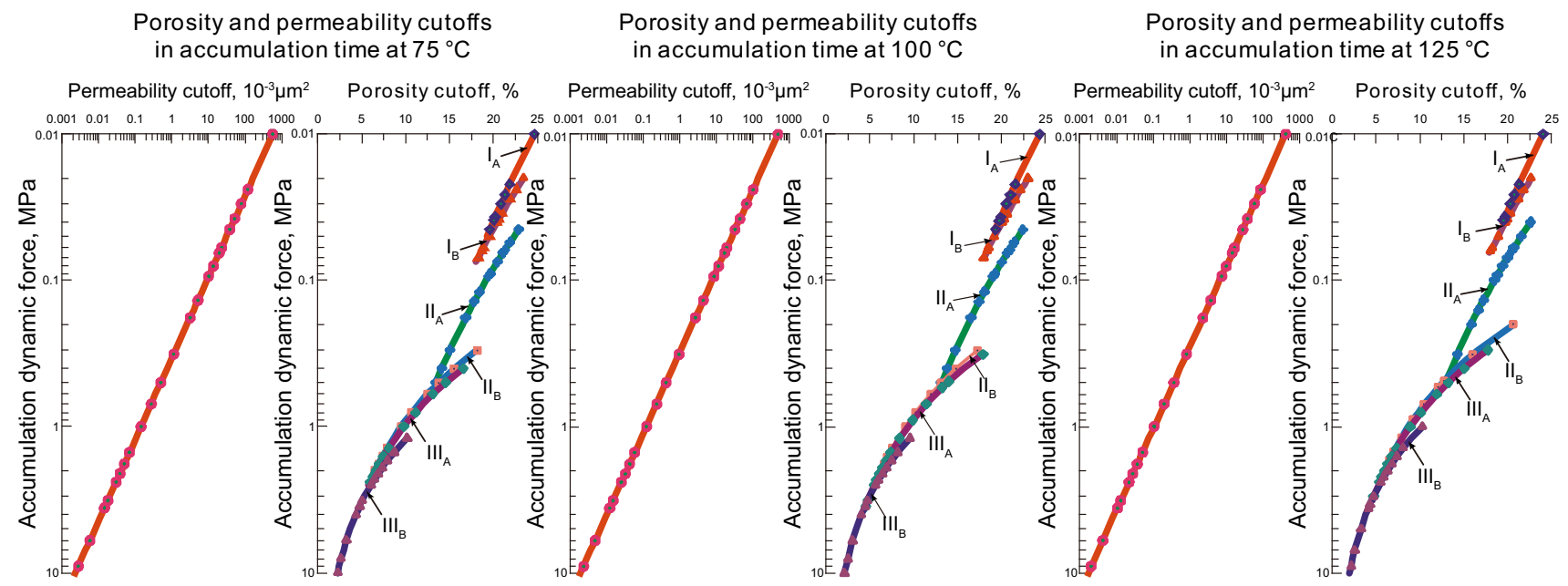

Fig. 13 Cutoff-values for porosity and permeability under different formation temperatures of the low permeability $\mathrm{Es}_{3}^{\mathrm{Z}}$ turbidite reservoirs 


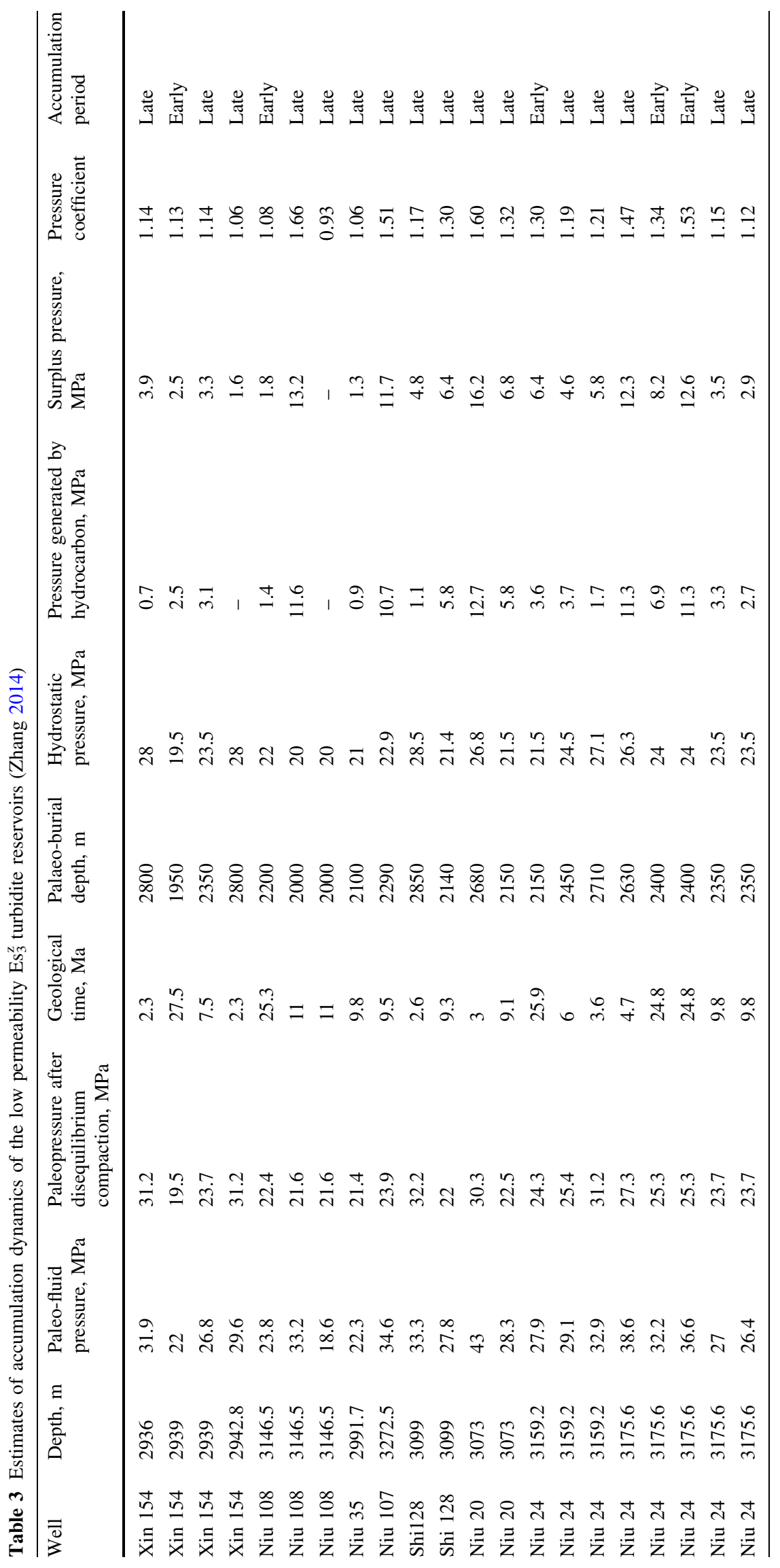



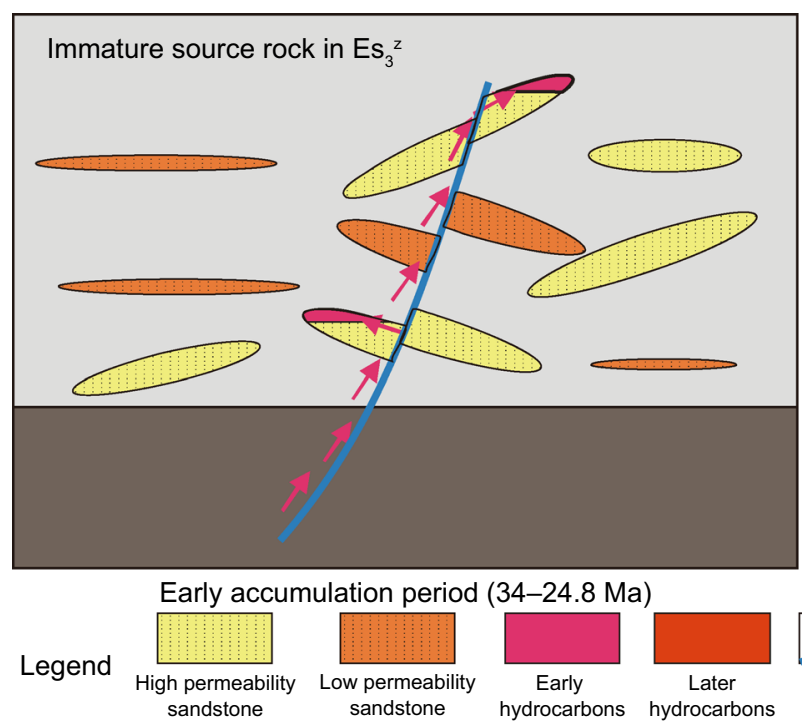

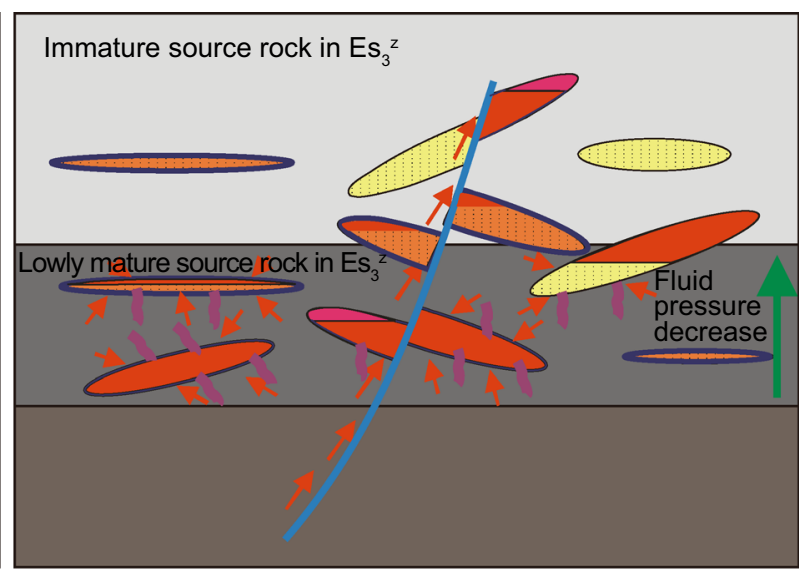

Later accumulation period (13.8-0 Ma)
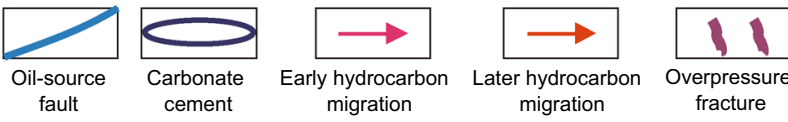

erpressure fracture

Fig. 14 The hydrocarbon accumulation patterns of low permeability $\mathrm{Es}_{3}^{\mathrm{Z}}$ turbidite reservoirs

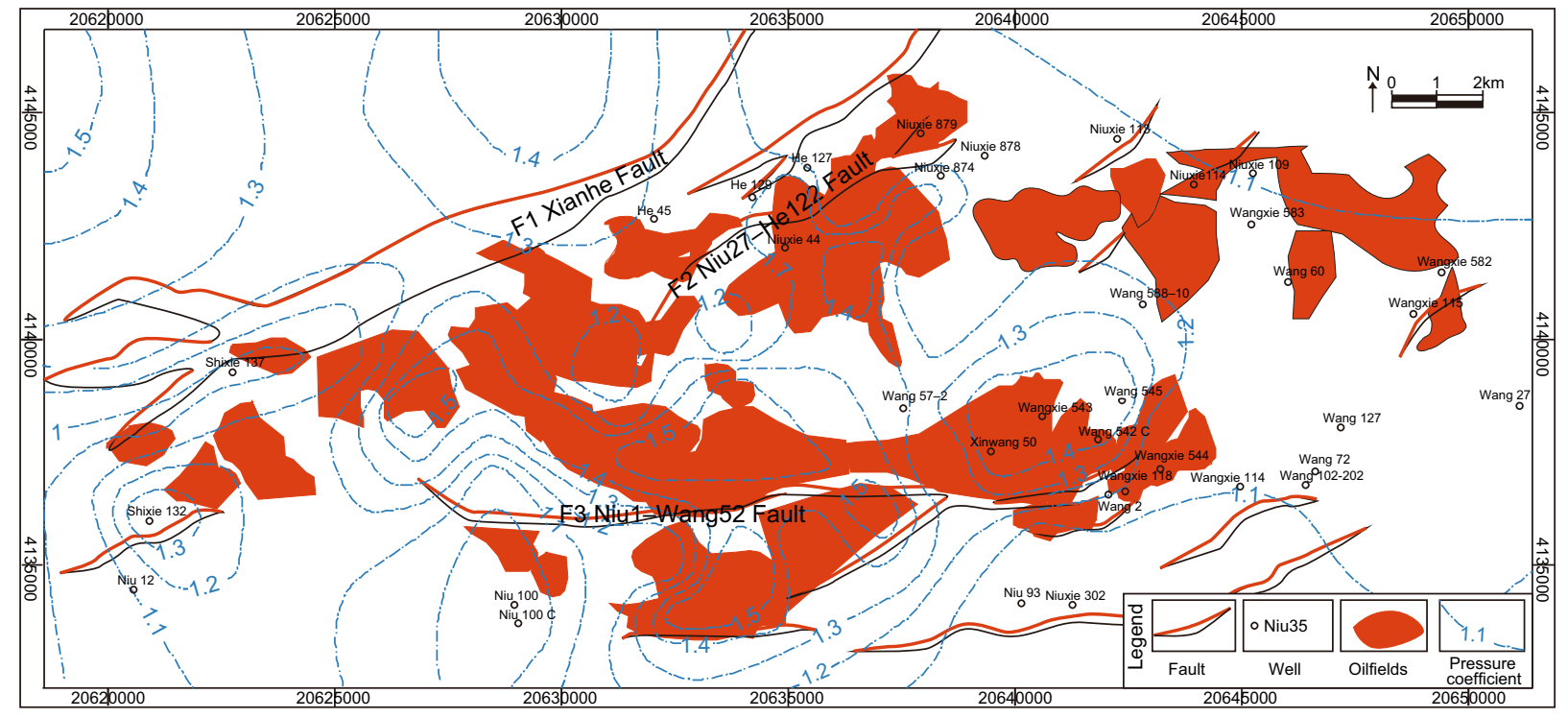

Fig. 15 The hydrocarbon distribution of the low permeability $\mathrm{Es}_{3}^{\mathrm{z}}$ turbidite reservoirs

the reservoir rocks, and the generated oil migrates from the lower part to the upper part (the reservoir). Faults in source rocks controlled the accumulation of reservoirs. The oil of the low permeability turbidite reservoirs in the late accumulation period comes from source rock in $\mathrm{Es}_{3}^{\mathrm{x}}, \mathrm{Es}_{4}^{\mathrm{s}}$, and $\mathrm{Es}_{3}^{\mathrm{z}}$ (Li et al. 2007). The source rocks are either below the reservoirs or both the source rocks and reservoir rocks are from the same formation.

Surplus pressure is the main accumulation dynamic in the early accumulation period. In the early accumulation period, the permeability of all reservoirs is higher than the cutoff-values for permeability. So, the sand bodies with fault development and connected with source rock in $\mathrm{Es}_{3}^{\mathrm{x}}$ and $\mathrm{Es}_{4}^{\mathrm{s}}$ accumulate hydrocarbon easily. Duo to heterogeneity caused by diagenetic processes (Liu et al. 2014a), hydrocarbon accumulation mostly occurred in the reservoirs with high permeability under the control of oil-source faults (Fig. 14). The fluid pressure increased by hydrocarbon generation is the main accumulation dynamic for isolated lenticular sand bodies without faults in the later accumulation period. All types of reservoirs with high accumulation dynamics can accumulate hydrocarbon. Reservoirs with diagenetic facies A and diagenetic facies B do not develop accumulation conditions at the low level of accumulation dynamics in the later accumulation period because the permeability of reservoir with diagenetic facies 
$\mathrm{A}$ and diagenetic facies $\mathrm{B}$ is lower than the maximum cutoff value. Surplus pressure is the main accumulation dynamic for sand bodies with fault development. All types of reservoirs with high accumulation dynamics can accumulate hydrocarbon. Reservoirs with diagenetic facies A and diagenetic facies $\mathrm{B}$ do not develop accumulation conditions at the low level of accumulation dynamics. Hydrocarbon always accumulated in reservoirs with high accumulation dynamics and oil-source faults development. Source rocks of the lower part of $\mathrm{Es}_{3}^{\mathrm{z}}$ have a high maturity when the burial depth of turbidite reservoir is more than $3000 \mathrm{~m}$ (Hao et al. 2006). The oil in the reservoirs came from the source rocks both at the same burial depth as the reservoirs and from a deeper burial depth than the reservoirs. The closer to the source rocks, the higher accumulation dynamics and the higher the hydrocarbon-filling degree. So isolated lenticular sand bodies can accumulate hydrocarbon. As the distances from source rocks to reservoirs increases, the accumulation dynamics for the reservoirs decrease and the hydrocarbon-filling degree decreases as well. The distance limit for an isolated lenticular sand body to accumulate hydrocarbon is about $225 \mathrm{~m}$ from the lower part of source rocks (Song et al. 2014) (Fig. 14). When the burial depth of turbidite reservoir is less than $3000 \mathrm{~m}$, the oil in the reservoirs came from the source rocks at deeper burial depth than the reservoirs. The oilsource faults controlled the accumulation of reservoirs. Taking the Niuzhuang subsag as an example, hydrocarbon always accumulated in reservoirs around the oil-source faults and areas near the center of subsag with high accumulation dynamics (Fig. 15).

\section{Conclusions}

(1) $\mathrm{Es}_{3}^{\mathrm{Z}}$ turbidite sandstones in the Dongying Sag are mostly lithic arkoses, and composed of mainly fine to medium sized grains. Low permeability reservoirs with middle to high porosity are most common, and the reservoir space is mainly primary pores. There are three broad types of pore throat structures which are subdivided into six sub-types. The major diagenetic events are mechanical compaction, cementation, replacement, and dissolution. The diagenetic paragenesis is siderite/micritic carbonate $\rightarrow$ first dissolution of feldspar $\rightarrow$ the beginning of the first hydrocarbon filling $\rightarrow$ first quartz overgrowth/authigenic kaolinite precipitation $\rightarrow$ the first group of carbonate cementation $\rightarrow$ the end of the first hydrocarbon filling $\rightarrow$ dissolution of quartz/feldspar overgrowth $\rightarrow$ second dissolution of feldspar and carbonate cementation $\rightarrow$ the beginning of the second hydrocarbon filling $\rightarrow$ second quartz overgrowth/authigenic kaolinite precipitation $\rightarrow$ the second group of carbonate cementation/pyrite cementation. Compaction existed throughout the entire burial and evolutional processes.

(2) In the early accumulation period, the reservoirs except for diagenetic facies A had middle to high permeability ranging from $10 \times 10^{-3} \mu \mathrm{m}^{2}$ to $4207.3 \times 10^{-3} \mu \mathrm{m}^{2}$, all the studied reservoirs can accumulate hydrocarbon. In the later accumulation period the reservoirs except for diagenetic facies $\mathrm{C}$ have low permeability ranging from $0.015 \times 10^{-3} \mu \mathrm{m}^{2}$ to $62 \times 10^{-3} \mu \mathrm{m}^{2}$, all the studied reservoirs can accumulate hydrocarbon at the high level of accumulation dynamics. Reservoirs with diagenetic facies A and diagenetic facies B do not develop accumulation conditions at the low level of accumulation dynamics.

(3) The hydrocarbon-filling degree is higher when the burial depth of turbidite reservoirs is more than $3000 \mathrm{~m}$. Isolated lenticular sand bodies can accumulate hydrocarbon. When the burial depth of turbidite reservoirs is less than $3000 \mathrm{~m}$, isolated lenticular sand bodies cannot accumulate hydrocarbon. Hydrocarbons always accumulate in reservoirs around the oil-source faults and areas near the center of subsags with high accumulation dynamics.

Acknowledgments This work is supported by the National Natural Science Foundation of China (Grant No. U1262203), the National Science and Technology Special Grant (No. 2011ZX05006-003), the Fundamental Research Funds for the Central Universities (Grant No. 14CX06070A), and the Chinese Scholarship Council (No. 201506450029). The Shengli Oilfield Company of SINOPEC provided all the related core samples and some geological data. The authors wish to thank editors and reviewers for their thorough and very constructive review that greatly improved the manuscript.

Open Access This article is distributed under the terms of the Creative Commons Attribution 4.0 International License (http://crea tivecommons.org/licenses/by/4.0/), which permits unrestricted use, distribution, and reproduction in any medium, provided you give appropriate credit to the original author(s) and the source, provide a link to the Creative Commons license, and indicate if changes were made.

\section{References}

Bao XH, Hao F, Fang Y, et al. Evolution of geopressure fields in the Niuzhuang Sag of the Dongying Depression and their effect on petroleum accumulation. Earth Sci J China Univ Geosci. 2007;32(2):241-6 (in Chinese).

Bjørlykke K. Relationships between depositional environments, burial history and rock properties. Some principal aspects of diagenetic process in sedimentary basins. Sed Geol. 2014;301:1-14. 
Bloch S, Lander RH, Bonnell L. Anomalously high porosity and permeability in deeply buried sandstone reservoirs: origin and predictability. AAPG Bull. 2002;86(2):301-28.

Cai LM. The Dynamic Process of Hydrocarbon Migration and Accumulation in Lenticular Sandstones of the Third Middle Member of the Shahejie Formation in the Niuzhuang Subsag, Dongying Depression. Wuhan: China University of Geosciences; 2009 (in Chinese).

Cai LM, Chen HH, Li CQ, et al. Reconstruction of the paleo-fluid potential field of $\mathrm{Es}_{3}$ in the Dongying Sag of the Jiyang depression with systematic fluid inclusion analysis. Oil Gas Geol. 2009;30(1):19-25 (in Chinese).

Cao YC. Vertical evolution and quantitative characterization of clastic reservoirs in the Shahejie Formation, Dongying Sag. Dongying: Geological Science Research Institute of Shengli Oilfield, Sinopec; 2010 (in Chinese).

Cao YC, Chen L, Wang YZ, et al. Diagenetic evolution of $\mathrm{Es}_{3}$ reservoirs and its influence on reservoir properties in the northern Minfeng sub-sag of the Dongying Sag. J China Univ Pet. 2011;35(5):6-13 (in Chinese).

Cao YC, Yuan GH, Wang YZ, et al. Genetic mechanisms of low permeability reservoirs of the Qingshuihe Formation in the Beisantai area, Junggar Basin. Acta Pet Sinica. 2012;33(5):758-71 (in Chinese).

Cao YC, Ma BB, Wang YZ, et al. Genetic mechanisms and classified evaluation of low permeability reservoirs of $\mathrm{Es}_{4}^{\mathrm{s}}$ in the north zone of Bonan Sag. Nat Gas Geosci. 2013;24(5):865-78 (in Chinese).

Cao YC, Yuan GH, Li XY, et al. Characteristics and origin of abnormally high porosity zones in buried Paleogene clastic reservoirs in the Shengtuo area, Dongying Sag, East China. Pet Sci. 2014;11:346-62.

Chen HH. Microspectrofluorimetric characterization and thermal maturity assessment of individual oil inclusions. Acta Pet Sin. 2014;35(3):584-90 (in Chinese).

Folk RL. Petrology of sedimentary rocks. Austin: Hemphill; 1974. p. 182.

Gao YJ, Wang YS, Yu YL, et al. Coupling of driving force and resistance for the migration of oil and gas at the periods of hydrocarbon accumulation in the southern slope of the Dongying Sag: taking the Jin 8-Bin 188 section as an example. Geoscience. 2010;24(6):1148-56 (in Chinese).

Giles MR, de Boer RB. Origin and significance of redistributional secondary porosity. Mar Pet Geol. 1990;7:378-97.

Girard J, Munz IA, Johansen H, et al. Diagenesis of the Hild Brent sandstones, northern North Sea: isotopic evidence for the prevailing influence of deep basinal water. J Sediment Res. 2002;72(6):746-59.

Guo XW, Liu KY, He S, et al. Petroleum generation and charge history of the northern Dongying Depression, Bohai Bay Basin, China: insight from integrated fluid inclusion analysis and basin modelling. Mar Pet Geol. 2012;32(1):21-35.

Guo J, Zeng JH, Song GQ, et al. Characteristics and origin of carbonate cements in the Shahejie Formation of the Central Uplift Belt in the Dongying Depression. Earth Sci J China Univ Geosci. 2014;39(5):565-76 (in Chinese).

Hao XF, Chen HH, Gao QL, et al. Micro-charging processes of hydrocarbon in the Niuzhuang lentoid sandy reservoirs, Dongying depression. Earth Sci $J$ China Univ Geosci. 2006;31(2):182-90 (in Chinese).

Hao F, Zou HY, Gong ZS. Preferential petroleum migration pathways and prediction of petroleum occurrence in sedimentary basins: a review. Pet Sci. 2010;7:2-9.

Higgs KE, Zwingmann H, Reyes AG, et al. Diagenesis, porosity evolution, and petroleum emplacement in tight gas reservoirs,
Taranaki Basin, New Zealand. J Sediment Res. 2007;77:1003-25.

Jiang YL, Liu H, Zhang Y, et al. Analysis of the petroleum accumulation phase in the Dongying Sag. Oil Gas Geol. 2003;24(3):215-8 (in Chinese).

Lander RH, Larese RE, Bonnell LM. Toward more accurate quartz cement models: the importance of euhedral versus noneuhedral growth rates. AAPG Bull. 2008;92(11):1537-63.

Li SM, Qiu GQ, Jiang ZX, et al. Origin of the subtle oils in the Niuzhuang Sag. Earth Sci J China Univ Geosci. 2007;32(2):241-6 (in Chinese).

Liu MJ, Liu Z, Wang B, et al. The controls of sandstone paleoporosity in the accumulation period to hydrocarbon distribution: a case study from the $\mathrm{Es}_{3}^{\mathrm{Mid}}$ in the Niuzhuang Sag, Dongying Depression. Chin J Geol. 2014a;49(1):147-60 (in Chinese).

Liu MJ, Liu Z, Sun XM, et al. Paleoporosity and critical porosity in the accumulation period and their impacts on hydrocarbon accumulation - A case study of the middle $\mathrm{Es}_{3}$ member of the Paleogene Formation in the Niuzhuang Sag, Dongying Depression, Southeastern Bohai Bay Basin, East China. Pet Sci. 2014b;11:495-507.

Liu MJ, Liu Z, Liu JJ, et al. Coupling relationship between sandstone reservoir densification and hydrocarbon accumulation: a case from the Yanchang Formation of the Xifeng and Ansai areas, Ordos Basin. Pet Explor Dev. 2014c;41(2):168-75 (in Chinese).

McMahon PB, Chapelle FH, Falls WF, et al. Role of microbial processes in linking sandstone diagenesis with organic-rich clays. J Sediment Pet. 1992;62(1):1-10.

Meng WB, Lu ZX, Tang Y, et al. Reservoir permeability prediction based on sandstone texture classification. J China Univ Pet. 2013;37(2):1-6 (in Chinese).

Pan GF, Liu Z, Fan S, et al. The study of lower limit of porosity for oil accumulation in the Chang- 8 Member, Zhenjing Area, Ordos Basin. Geoscience. 2011;25(2):271-8 (in Chinese).

Qi BW, Lin CM, Qiu GQ, et al. Reservoir diagenesis of the intermediate section in Member 3 of the Paleogene Shahejie Formation in the Niuzhuang Sub-sag, Shandong Province. J Palaeogeogr. 2006;8(4):519-30 (in Chinese).

Song GQ, Hao XF, Liu KQ, et al. Tectonic evolution, sedimentary system and petroleum distribution patterns in a dustpan-shaped rift basin: a case study from Jiyang Depression, Bohai Bay Basin. Oil Gas Geol. 2014;35(3):303-10 (in Chinese).

Sui FG, Hao XF, Liu Q, et al. Formation dynamics and quantitative prediction of hydrocarbons of the superpressure system in the Dongying Sag. Acta Geol Sin (English Edition). 2008;82(1):164-73.

Surdam RC, Crossey LJ, Hagen SE, et al. Organic-inorganic interactions and sandstone diagenesis. AAPG Bull. 1989;73(1):1-12.

Taylor TR, Giles MR, Hathon LA, et al. Sandstone diagenesis and reservoir quality prediction: models, myths, and reality. AAPG Bull. 2010;94(8):1093-132.

Tournier F, Pagel M, Portier E, et al. Relationship between deep diagenetic quartz cementation and sedimentary facies in a Late Ordovician glacial environment (Sbaa Basin, Algeria). J Sediment Res. 2010;80:1068-84.

Wang YZ. Genetic mechanism and evolution model of the secondary pore development zone of the Paleogene in the North Zone, Dongying Depression. Qingdao: China University of Petroleum (Huadong); 2010 (in Chinese).

Wang JM, Liu SF, Li J, et al. Characteristics and causes of Mesozoic reservoirs with extra-low permeability and high water cut in northern Shaanxi. Pet Explor Dev. 2011;38(5):583-88 (in Chinese).

Wang YZ, Cao YC, Xi KL, et al. A method for estimating porosity evolution of clastic reservoirs with geological time: a case study from the upper $\mathrm{Es}_{4}$ submember in the Dongying Depression, 
Jiyang Subbasin. Acta Pet Sin. 2013a;34(6):1100-111 (in Chinese).

Wang JD, Li SZ, Santosh M, et al. Lacustrine turbidites in the Eocene Shahejie Formation, Dongying Sag, Bohai Bay Basin, North China Craton. Geol J. 2013b;48(5):561-78.

Wang YZ, Cao YC, Song GQ, et al. Analysis of petrophysical cutoffs of reservoir intervals with production capacity and with accumulation capacity in clastic reservoirs. Pet Sci. 2014a;11:211-21.

Wang YZ, Cao YC, Ma BB, et al. Mechanism of diagenetic trap formation in nearshore subaqueous fans on steep rift lacustrine basin slopes-A case study from the Shahejie Formation on the north slope of the Minfeng Subsag, Bohai Basin, China. Pet Sci. 2014b;11:481-94.

Wilkinson M, Haszeldine RS, Fallick AE. Hydrocarbon filling and leakage history of a deep geopressured sandstone, Fulmar Formation, United Kingdom North Sea. AAPG Bull. 2006;90(12):1945-61.

Yang ZM, Yu RZ, Su ZX, et al. Numerical simulation of the nonlinear flow in ultra-low permeability reservoirs. Pet Explor Dev. 2010;37(1):94-8 (in Chinese)

Yang T, Cao YC, Wang YZ, et al. Status and trends in research on deep-water gravity flow deposits. Acta Geol Sin (English Edition). 2015;89(2):801-22.

Yuan GH, Cao YC, Xi KL, et al. Feldspar dissolution and its impact on physical properties of Paleogene clastic reservoirs in the northern slope zone of the Dongying Sag. Acta Pet Sin. 2013;35(4):853-66 (in Chinese).
Yuan GH, Gluyas J, Cao YC, et al. Diagenesis and reservoir quality evolution of the Eocene sandstones in the northern Dongying Sag, Bohai Bay Basin, East China. Mar Pet Geol. 2015;62:77-89.

Zhang SW, Wang YS, Shi DS, et al. Fault-fracture mesh petroleum plays in the Jiyang Superdepression of the Bohai Bay Basin, eastern China. Mar Pet Geol. 2004;21(6):651-68.

Zhang JL, Li DY, Jiang ZQ. Diagenesis and reservoir quality of the fourth member sandstones of Shahejie Formation in Huimin Depression, Eastern China. J Cent South Univ Technol. 2010;17(1):169-79.

Zhang Q, Zhu XM, Steel RJ, et al. Variation and mechanisms of clastic reservoir quality in the Paleogene Shahejie Formation of the Dongying Sag, Bohai Bay Basin, China. Pet Sci. 2014;11:200-10.

Zhang XF. Synergistic diagenesis of argillaceous source rocks and sandstones of the Shahejie Formation in the southern Dongying Depression and their petroleum geological significance. Ph.D. Thesis. Nanjing: Nanjing University; 2012 (in Chinese).

Zhang W. The heterogeneity of the turbidite in the Niuzhuang area and its control action on the hydrocarbon accumulation. Dongying: Post-doctoral Scientific Research Workstation of Shengli Oilfield, Sinopec; 2014 (in Chinese).

Zhuo QG, Jiang YL, Sui FG. Research on patterns of reservoiring dynamics in sand lens reservoirs in the Dongying Sag. Oil Gas Geol. 2006;27(5):620-9 (in Chinese). 